\title{
Novel Starch/Chitosan/Aloe Vera Composites as Promising Biopackaging Materials
}

\author{
Dagmara Bajer $^{1} \mathbb{C} \cdot$ Katarzyna Janczak ${ }^{2} \cdot$ Krzysztof Bajer $^{2}$
}

Published online: 30 January 2020

(c) The Author(s) 2020

\begin{abstract}
Edible films based on potato starch, chitosan and Aloe vera gel (AV) as modifiers were evaluated towards their potential application in food or cosmetics industry. The films, with different AV gel concentration were prepared by casting method. The influence of UV radiation on samples chemical structure was analyzed. The surface morphology was observed with AFM method. The chemical structure and molecular arrangement of mixture components were analyzed with ATR-FTIR spectroscopy and X-ray diffraction. Hydrogen bond interactions among the film components, conformational rearrangements as well as changes in crystallinity degree were confirmed. A study of thermal resistance showed the delay of degradation observed together with an increase AV gel amount and after UV-irradiation. The hydrophilic character of the samples was proved. Water solubility slightly depends on the AV concentration in films, and it decrease after UV-irradiation. All the samples with AV gain the increase resistance to microbial action.
\end{abstract}

Keywords Starch $\cdot$ Chitosan $\cdot$ Aloe vera $\cdot$ Composites $\cdot$ Crosslinking $\cdot$ Thermal resistance $\cdot$ Microbial resistance

\section{Introduction}

Active, bio-friendly and natural-based materials are one of the innovative concepts in the field of research on packaging materials. Development of systems involving the employment of completely biodegradable polymers and natural bioactive components is currently a major challenge for plastic processing plants and packaging manufacturers. Due to its antimicrobial components, such an active packaging material can be an effective way to protect food or other perishable products (e.g. cosmetics) against accelerated biodegradation caused by activity of microorganisms which colonize the product surface.

The possibility of reduction in the use of preservatives directly in the material, which undoubtedly increases the final product safety by protecting consumers against developing skin and food allergies, is an additional advantage of

Dagmara Bajer

cellulose@ poczta.onet.pl

1 Nicolaus Copernicus University, Gagarin 7, Toruń 87-100, Poland

2 ŁUKASIEWICZ Research Network, Institute for Engineering of Polymer Materials and Dyes, Maria Skłodowska-Curie 55, Toruń 87-100, Poland such packaging. However, current trends have to take into account not only biodegradability, but also the oxidative resistance of such materials. The combined use of natural raw materials, i.e. antioxidants, anti-microbial agents incorporated into the biopolymer matrix constituting a base could contribute to an increase in their application efficiency. Currently, obtaining naturally originating materials resistant to photo- and bio-degradation, simultaneously characterized by the desired mechanical strength, capabilities and constant processing parameters, transparency and physico-chemical properties (e.g. hydrophobicity, permeability to steam and gases, solubility, wettability, adhesion, cohesion etc.) constitutes a huge challenge to researches [1].

Starch, a natural polysaccharide, is one of the most commonly occurring biopolymers. As a raw material of differentiated botanical origins, a reserve material in most plants, it has become a basic nutrient for mammals [2]. Although the chemical structure of starch is commonly known, its origin and source are responsible for a large variety of its chemical composition (amylose to amylopectin ratio), (poly)dispersity, granules shape and size, as well as its molecular order and average molecular weight.

Both, starch and its chemically and physically modified products, could find their applications in many sectors of industry (e.g. food, cosmetics, paper, and textile) 
and, more recently, as raw materials for biodegradable packaging production due to their availability, low acquisition costs and biodegradation. Despite many advantages, starch remains a difficult processing material owing to its cold-water insolubility, susceptibility to retrogradation, gelatinization, and high hydrophilicity [2, 3]. Moreover, its processing is characterized by high variability and instability and does not give reproducible results, which directly results from the botanical origin of starch or climatic conditions of plants growth. Starch-based films are brittle and not resistant to water activity, which directly limits the possibility of its industrial use.

Thus, a suitable physico-chemical modification of native starch is aimed at modifying its properties according to industrial requirements and applicability [4-6]. It concerns improving the starch processing methods but it is also intended to obtain a material preventing biocompatible or antimicrobial properties. For this purpose, chitosan with its good gel- and film-forming abilities, anti-microbial and antioxidative properties as well as biodegradability seems to be a good modifier and a valuable material which has gained particular scientific attention. Its functional properties have been widely reported in literature in recent years [7-14]. Moreover, it is absolutely safe and non-toxic; thus, there are no contraindications to its use in for food packaging production. Furthermore, as expected, chitosan can improve the mechanical properties of starch films which could strongly affect the possibility of its use on a large scale [2, 13, 14]. Due to its higher hydrophobicity, if compared with that of starch, chitosan reduces water vapor transport and consequently increases resistance to moisture in starch/chitosan blends $[9,10]$.

A possibility to bond chemically with bioactive particles owing to the presence of reactive carbonyl and/or hydroxyl groups is an important advantage of such biopolymers. Thus, anti-bacterial properties of starch-/chitosan-based films could be intensified with biocompatible Aloe vera (AV) gel incorporated into the polymer matrix. It broadens the scope of applications for such biomaterial which turn out to be effective also for therapeutic and dressing purposes. Aloe vera plant is characterized by antimicrobial activity due to the presence of antiseptic ingredients i.a. salicylic acid, cinnamonic acid, sulfur, lueol. Moreover, its components such as glycoproteins, prostaglandins, muccopolysaccharides and gamma-linoleic acid are effective against E.coli, K. pneumoniae and $S$. aureus, whereas its anti-oxidative potential results from phenolic and polyssaccharide components, for example mannan, acemannan, glucomannan. In addition, by acting synergistically with other substances present in Aloe vera gel, e.g. enzymes or vitamins, biopolymer (starch/chitosan) films gain many pharmacological properties which are of great interest to medicine as well as food, cosmetic and pharmaceutical industries $[15,16]$.
Plant extracts which Aloe vera gel contains are a rich source of antioxidants, e.g. flavonoids, flavonols, polyphenols, organic acids (for example citric acid), etc., which can additionally improve plasticizing properties and influence bio-based films flexibility [17-20].

In addition to the aforementioned ingredients, there are more than 200 chemically active substances in Aloe vera gel. Among them, enzymes and minerals, essential and nonessential amino acids, sterols, saponins, anthraquinones (aloin, emodin) etc., can be listed. They are a part of dry, only $0.5-1.5 \%$ solid fraction, while water is the dominant component (98.5-99.5\%) of the gel [16, 20].

Producing dressing materials based on biopolymers with $\mathrm{AV}$ gel incorporated in polymer films or hydrogels are a new research challenge. They are expected to elicit wound healing acceleration protecting at the same time against microbial attack; thus, such materials are of great interest for tissue engineering, drug delivery, and wound-dressings purposes.

A novel systems based on Aloe vera gel blended into the chitosan matrix was explored, and a strong interaction between these two components was proved [21, 22]. This combination caused a decrease in water solubility and vapor permeability noticed together with an increase in Aloe gel concentration. Moreover, mechanical properties of the prepared films were improved. Additionally, antimicrobial activity against $S$. aureus was higher in chitosan membranes enriched with higher Aloe vera gel content.

The objective of this study was to modify natural potato starch with chitosan and Aloe vera gel in order to obtain a new intelligent primary material presenting antimicrobial and antioxidant properties.

Such desirable features may enable its practical application in agriculture, food and cosmetic packaging industries as well as pharmaceutical industry.

Analyses of surface properties and morphology (ATR-FTIR spectroscopy, contact angle measurements, AFM micrographs), water swelling, thermal behavior, or susceptibility to UV radiation as well as microbial activity will provide significant information.

\section{Materials and Methods}

\section{Materials}

Potato starch was purchased from Cargill Poland Sp. z o.o. Wet basis of starch was $17 \%$, and amylose content in dry basis was $26.1 \%$.

Technical glycerin with density of $1.26 \mathrm{~g} / \mathrm{cm}^{3}$ and purity $96 \%$ was purchased in POCh S.A.

Chitosan with the molecular weight equal to $411000 \mathrm{~g} /$ mol and deacetylation degree equal $82 \% \pm 1.7 \%$ (both 
quantities were determined in our laboratory) was purchased from SIGMA ALDRICH [23].

Aloe vera gel (99.7\%) was produced by Synoptis Pharma Sp. z o.o. (Poland) from Aloe Barbadensis (Mexico).

\section{Film Preparation}

$4 \mathrm{~g}$ potato starch was dispersed in $100 \mathrm{ml}$ of distilled water and stirred for $20 \mathrm{~min}$ at room temperature, and then heated at $100{ }^{\circ} \mathrm{C}$ for $30 \mathrm{~min}$. After starch gelling, the plasticizer (glycerol) (20\% ww.) was added and stirred for $5 \mathrm{~min}$.

Chitosan was dissolved in $20 \mathrm{ml} 2 \%$ acetic acid and added gradually to the starch and glycerol mixture during stirring at $60{ }^{\circ} \mathrm{C}$ (the chitosan amount was $5 \mathrm{~g}$ per $100 \mathrm{~g}$ of starch).

In the final stage Aloe vera gel was added in the following concentration: $0,10,20,30,40$ and $50 \mathrm{~g}$ per $100 \mathrm{~g}$ starch. $\mathrm{AV}$ gel was incorporated into the starch base after cooling the mixture up to $30^{\circ} \mathrm{C}$.

The following mixtures were obtained: starch/chitosan (described as SC), starch/chitosan with 10\% Aloe vera gel (SCA 10), starch/chitosan with 20\% Aloe vera gel (SCA 20), starch/chitosan with 30\% Aloe vera gel (SCA 30), starch/chitosan with 40\% Aloe vera gel (SCA 40), and starch/chitosan with 50\% Aloe vera gel (SCA 50).

Obtained emulsions were poured into Petri dishes and allowed to dry at room temperature.

\section{UV-Irradiation}

Starch/chitosan/Aloe vera gel films were exposed to lowpressure mercury vapor lamp TUV-30 W (Philips, Holland) at room temperature and in air atmosphere. The wavelength and intensity of emitted radiation was $254 \mathrm{~nm}$ and $33.4 \mathrm{~W} /$ $\mathrm{m}^{2}$, respectively. The time of exposure was 5- and 24-h.

\section{FTIR-ATR Spectroscopy}

FTIR-ATR spectra of starch/chitosan-based films (irradiated and non-irradiated with UV light) were collected using Spectrum Two ${ }^{\mathrm{TM}}$ (PerkinElmer, Waltham, MA, USA), equipped with ATR device containing diamond crystal. All the spectra were recorded at a resolution of $4 \mathrm{~cm}^{-1}$ in the range of $400-4000 \mathrm{~cm}^{-1}$ and with a scan number of 16 . Obtained results were analyzed with Perkin Elmer software.

\section{Thermal Properties (Thermogravimetry)}

The thermal stability of starch/chitosan-based samples was conducted with TA Instrument SDT2960 Simultaneous Analyzer. The samples of 5-10 mg weights were heated from $20{ }^{\circ} \mathrm{C}$ to $600{ }^{\circ} \mathrm{C}$ at a heating rate of $6{ }^{\circ} \mathrm{C} / \mathrm{min}$ in nitrogen atmosphere. TG, DTG and DTA have been recorded simultaneously, and the following parameters were determined:
$\mathrm{T}_{\max },{ }^{\circ} \mathrm{C}$ is the temperature of maximal rate of the first decomposition stage. $\Delta \mathrm{m}_{\mathrm{I}}, \%$ is the weight loss of I stage. $\mathrm{T}_{0 \mathrm{II}},{ }^{\circ} \mathrm{C}$ is the temperature of initial rate of the second (main) decomposition stage. $\mathrm{T}_{\operatorname{maxII}},{ }^{\circ} \mathrm{C}$ is the temperature of maximal rate of the second (main) decomposition stage. $\Delta \mathrm{m}_{\mathrm{II}}, \%$ is the weight loss of II stage.

\section{Atomic Force Microscopy (AFM)}

AFM images were obtained with MultiMode NanoScope III, Veeco Metrology Inc. (USA) with silicon probe (Veeco) in tapping mode in air, at room temperature. The AFM studies allowed to observe surface changes of tested samples after 5and 24-h UV irradiation. The scanning area was $5 \times 5[\mu \mathrm{m}]$. In addition, the roughness parameters: an arithmetic mean $\left(\mathrm{R}_{\mathrm{a}}\right)$, and a root mean square $\left(\mathrm{R}_{\mathrm{q}}\right)$ were calculated.

\section{Contact Angle Measurements}

Surface properties were established with DSA G10 goniometer (Krüss GmbH, Germany). The embedded drop procedure was used as follows: a drop of glycerine $(3 \mu \mathrm{L})$ or diiodomethane $(2 \mu \mathrm{L})$ was placed onto a sample surface with microsyringe and the value of contact angle was determined on the basis of the obtained image of the liquid drop. Measurements of contact angle were conducted for nonirradiated and UV-treated samples. The results, which were an average of 6 measurements (the deviation from the average was within $\pm 2^{\circ}$ ), allowed to calculate the surface free energy and its polar and dispersion components according to Owens-Wendt method [24]. For this purpose, the instrument software (Kruss GmbH, Hamburg, Germany) was used.

\section{X-Ray Diffraction Measurement (XRD)}

Crystalline structure of starch-based films was characterized with X`Pert PRO diffractometer (Malvern Panalytical, Almelo, Holland) using $\mathrm{CuK}_{\alpha}$ radiation (wavelength of $1.5240 \AA$, nickel filtered). $2 \theta$ was ranged from 5 to $60^{\circ}$. The High Score software was used to perform XRD analysis. Crystallinity degree $\left(\mathrm{X}_{\mathrm{c}}\right)$ was calculated as a ratio between total area of crystalline peaks and total diffractogram area (as a sum of crystalline and amorphous halo) and expressed as percentage.

\section{Water Solubility (\%)}

Water solubility (WS) is an indicator of samples hydrophilicity/hydrophobicity and as indispensable parameter it is necessary to define it for commercial application of the tested material. WS was determined according to the procedure described in literature with a slight modification [19, 25]. Approximately $0.5 \mathrm{~g}$ of all starch based films were dried in 
an oven at $85 \pm 1{ }^{\circ} \mathrm{C}$ for $24 \mathrm{~h}$. After drying the films were weighted and immersed in $50 \mathrm{~mL}$ distilled water for $24 \mathrm{~h}$ at $25^{\circ} \mathrm{C}$, therewith dried again in analogous terms and conditions. All tests were conducted in triplicate. The dry matter was weighted and water solubility (WS, \%) was calculated by the following equation (Eq. 1):

WS $(\%)=\left[\left(\mathrm{m}_{0}-\mathrm{m}_{1}\right) / \mathrm{m}_{0}\right] \cdot 100$

where, WS is the water solubility [\%], $\mathrm{m}_{0}$ is the initial dry weight $[\mathrm{g}], \mathrm{m}_{1}$ is the final dry weight $[\mathrm{g}]$.

\section{Microbiological Analysis}

The assessment of microorganisms activity on the starch film was carried out on the basis of PN-EN ISO 846, 2002 (Plastics. Evaluation of the action of microorganisms). Two types of microorganisms were grafted onto starch films: Bacillus sp.- a strain of soil bacteria originating from anthropogenically degraded areas, exhibiting high capability of producing hydrolytic enzymes and Fusarium culmorum which is a microscopic fungus, a corn pathogen whose natural nutrient source is starch. In the studies, the influence of fungi on the starch film was analyzed according to the standard method called Mycelium growth test in which material samples are incubated in the presence of microscopic fungi grown on a minimal medium amount, without a carbon source. In such an arrangement, the microorganisms can only be grown using a polymer compound as a sole carbon source, thereby deteriorating its properties. Similarly, in studies concerning the bacterial influence on the film, a "resistance to bacteria" analysis of is carried out based on the minimum substrate concentration.

The squares sized $40 \times 40 \mathrm{~mm}$ were cut from starch films. Such samples were sterilized under UV light using GS Gene Chamber Linker ${ }^{\mathrm{TM}}$ UV (Bio-Rad) for $90 \mathrm{~s}$ on each side.

According to the standard, a division into 3 groups of samples was applied: the group " 0 "— control samples, stored at normalized temperature and relative humidity $\left(23^{\circ} \mathrm{C} \pm 1\right.$, $50 \%$ humidity \pm 5 ); the group "I" - samples inoculated with microorganisms and incubated; the group "S" - unvaccinated samples, stored under the same conditions as the group "I". Due to the rapid progress in the deterioration process of films, the experiment duration was shortened from 4 to 2 weeks. Sterile Petri dishes of $90 \mathrm{~mm}$ diameter were filled with defective agar medium to a height of approx. $5 \mathrm{~mm}$. After the agar had set, the film was applied to the medium with one sterile group ("I" and "S") for each Petri dish, respectively. According to the standard, a bacterial or fungal spores suspension was applied to samples from the group I. The "S" and "I" groups were incubated in an incubator at $24^{\circ} \mathrm{C}$. After the first and second week, a visual assessment of the samples from each batch was carried out, according to the scale included in the standard, where the intensity of microorganisms growth was estimated on a scale form 0 (no visible height under the microscope) to 5 (intensive growth, overgrown microorganisms settle the whole sample surface).

After the 2nd week, additional samples were sterilized with UV light for $15 \mathrm{~min}$, then purified from agar and microorganisms with the use of a scalpel and swabs. The samples were then left in the desiccator overnight.

For visual evaluation, photographs were taken and the automatic colony counter SCAN® 1200 (Interscience, France) was used. A Nikon Eclipse 50i microscope (Japan) was used for microscopic observations. To assess the loss of mass, the tested samples were weighed before and after incubation on an analytical balance to the nearest $0.1 \mathrm{mg}$. A percentage change in mass was calculated for each sample.

\section{Results and Discussion}

\section{FTIR-ATR Analyses}

FTIR-ATR spectroscopy was used to determine and characterize the chemical structure and molecular interactions in blends as well as to register the changes induced by UV-irradiation. The main, characteristic absorption bands appear in the range adequate for all the components of the mixture: starch, Aloe vera gel and chitosan. Representative spectra obtained for starch/chitosan (SC) and starch/chitosan 50\%Ale vera gel (SCA 50) films are presented in the Fig. 1.

The Aloe vera gel, which is a highly hydrated organic material, exhibits quite a simple FTIR-ATR spectrum with two hydroxyl peaks: the broad and very intensive $-\mathrm{O}-\mathrm{H}$ stretching band in the spectral range of $3000-3600 \mathrm{~cm}^{-1}$ and the bending mode at $\sim 1635 \mathrm{~cm}^{-1}$, characteristic for free water. More detailed characteristics were obtained after its drying $\left(50{ }^{\circ} \mathrm{C}, 6 \mathrm{~h}\right)$ as a result of which $0.63 \%$ of the initial dry matter was obtained (Fig. 2).

Both, Aloe vera gel as well as starch, show the broad, very intense band at $3000-3600 \mathrm{~cm}^{-1}$, attributed to hydroxyl groups and adsorbed water. A clear assignment of characteristic modes in this spectral range is not trivial due to the fact that the hydroxyl stretching vibration bands overlap with the vibrations of $\mathrm{N}-\mathrm{H}$ stretching of amino-acids and $-\mathrm{NH}$ in chitosan also present in this region. This band can also be assigned to $-\mathrm{OH}$ stretching groups of Aloe vera constituents (e.g. uronic acid, mannonse or galactruonic acid) or phenolic groups in antraquinones such as aloin and emodin present in Aloe vera gel [26]. Such a wide range may also indicate the formation of intermolecular hydrogen bonds as a result of dipole-dipole attraction forces. It can be assumed that in the studied systems this type of bonds is formed between the same (i.e. starch-starch) or various molecules (Aloe vera polysaccharides-starch-chitosan-glycerin) interactions. 
Fig. 1 ATR-FTIR spectra of selected films: starch/chitosan (SC) and starch/chitosan with $50 \%$ Aloe vera gel (SCA 50) in the spectral range spectra range $4000-450 \mathrm{~cm}^{-1}$
Fig. 2 ATR-FTIR spectra of Aloe vera gel and dried Aloe vera in spectra range 4000 $450 \mathrm{~cm}^{-1}$
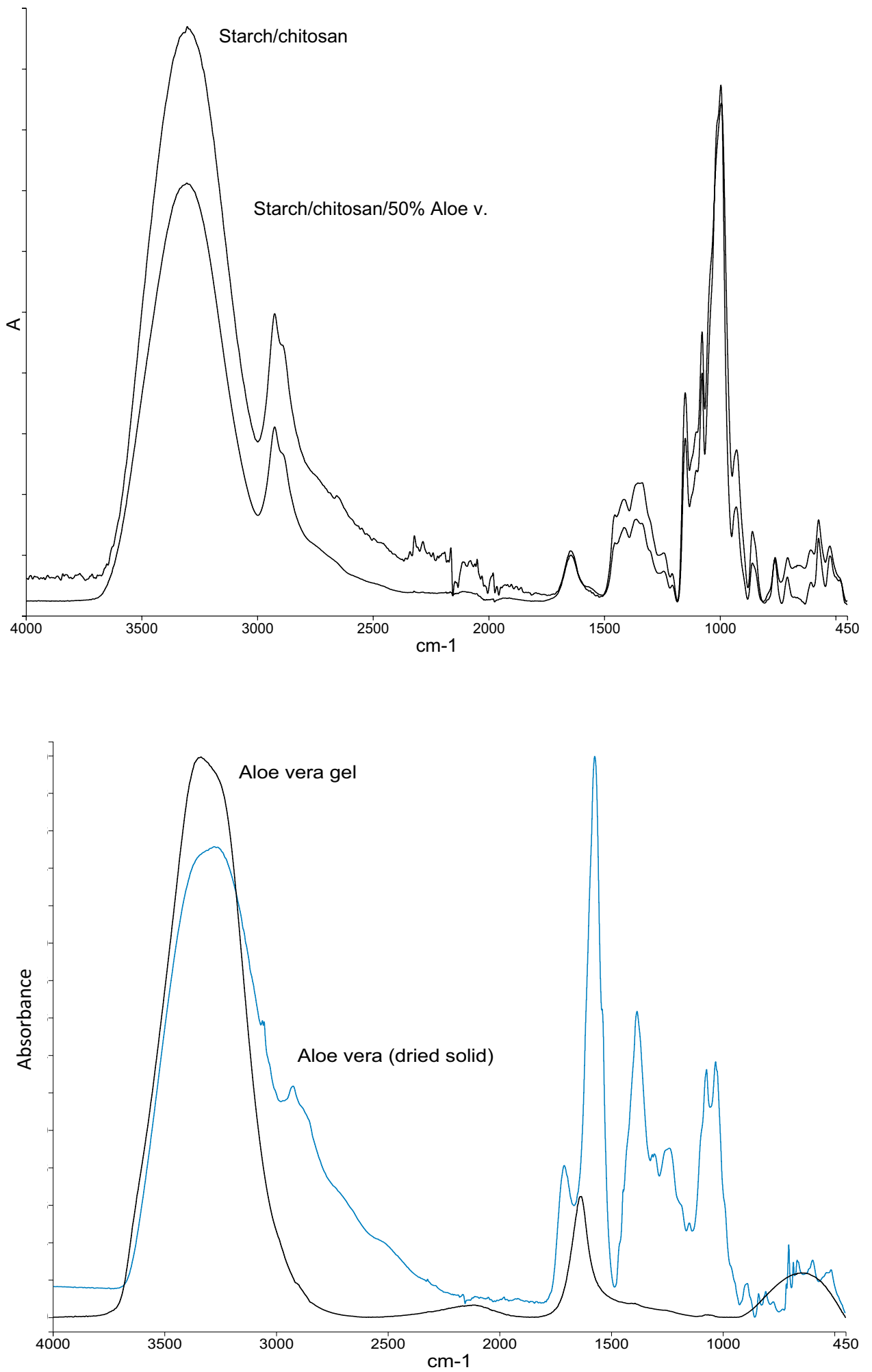

Analogous difficulties concern the spectral region between 900 and $1200 \mathrm{~cm}^{-1}$ where intense absorption bands are present due to the $\mathrm{C}-\mathrm{O}-\mathrm{C}$ stretching vibration of polysaccharide in Aloe vera gel but also in starch. This moiety, called "saccharide band", is sensitive to some conformational changes and is directly related to the crystal and amorphous phase in samples [4]. It is reported that the band at $\sim 991 \mathrm{~cm}^{-1}$, assigned to $\mathrm{C}-\mathrm{O}$ stretching vibration in the $\mathrm{C}-\mathrm{O}-\mathrm{C}$ anhydroglucose ring and intramolecular hydrogen bonding of $\mathrm{OH}$ groups at $\mathrm{C}-6$, is attributed to 
the amorphous structure in starch, whereas peaks at 1083 and $1158 \mathrm{~cm}^{-1}$ are associated with $\mathrm{C}-\mathrm{O}$ and $\mathrm{C}-\mathrm{OH}$ bending vibration and determine the proportion of the crystalline phase [27]. For all the samples, only the slight shift of the characterized bands maximum towards lower wavenumbers was noticed (values were 1077 and $1150 \mathrm{~cm}^{-1}$, respectively), which suggests the presence of some interactions between components.

The band at $991 \mathrm{~cm}^{-1}$ in samples without Aloe vera is shifted to higher frequencies $\left(996 \mathrm{~cm}^{-1}\right)$ in the spectra of the sample with $20 \%$ and $50 \%$ Aloe vera gel addition. It is probably due to some interactions between starch, chitosan or glycerol with $\mathrm{AV}$ gel macromolecules through $\mathrm{H}$-bonding which facilitates the mutual intercalation of substrates. This characteristic band is also sensitive to water content and it shifts into higher frequencies when water content increases. According to literature data, it appears at $991 \mathrm{~cm}^{-1}$ for the starch sample completely devoid of water [28]. Moreover, this band is sensitive to chain conformation or starch retrogradation, which consequently influences the obtained crystallinity results. The degree of starch order related to the intensities ratio $\left(\mathrm{R}_{1}\right)$ at the maximum of crystalline peak at $1150 \mathrm{~cm}^{-1}$ versus the amorphous band intensity at $994 \mathrm{~cm}^{-1}$ $\left(\mathrm{R}_{1}=\mathrm{I}_{[1150]} / \mathrm{I}_{[994]}\right)$ was calculated and listed in the Table 1 .

The higher $\mathrm{R}_{1}$ values correspond to a higher short-range of molecular order in the starch-based film [25, 27, 28]. Some difficulties with short-range crystallinity values determination from infra-red spectrum result from band overlapping, which may cause discrepancies in the obtained results.

The high intense band with the maximum at $1040 \mathrm{~cm}^{-1}$ (amplified after the deconvolution procedure) results from the presence of $\mathrm{C}-\mathrm{O}$ and $\mathrm{C}-\mathrm{OH}$ bonds in glucan units present in Aloe vera polysaccharide as well as in starch molecules. This band exists in all the spectra; thus, it can enable determination of differences in sample structures showing different composition and also comparison of the results after UV-irradiation. This band, as well as bands at about $1135 \mathrm{~cm}^{-1}, 1022 \mathrm{~cm}^{-1}$ and $861 \mathrm{~cm}^{-1}$, is sensitive to changes in starch crystallinity; therefore, the characteristics of its shapes, intensities or maxima shift are useful to determine the interactions and changes occurring in samples at the molecular level $[28,29]$. The ratio of the crystalline peak area or height (measured from the baseline) to areas or heights of peaks presenting lower sensitivity to crystallinity changes (at $1077 \mathrm{~cm}^{-1}$ or $\sim 994 \mathrm{~cm}^{-1}$ ) are helpful in determining the order of the sample and its sensitivity to external factors. The ratios of band intensities at $1040 \mathrm{~cm}^{-1}$ and $1012 \mathrm{~cm}^{-1}$ depend on the UV irradiation and Aloe vera concentration. One can observe the decrease in $\mathrm{I}_{[1040] /[1012]}$ ratio $\left(R_{2}\right)$ after $U V$-irradiation, but these changes are smaller for samples containing smaller amounts of Aloe vera gel (10\% AV gel), and higher with its increasing concentration (20-50\% AV) when compared to a pure starch-chitosan blend (Table 1).

For example, the band at the maximum in $1012 \mathrm{~cm}^{-1}$ on FTIR-ATR spectra of SC 50\%AV is most affected by UVradiation and becomes more intense after exposure (Fig. 3), but $I_{[1040] /[1012]}$ ratio is lower when compared to all other samples (Table 1). It may suggests the loss of an ordered structure after UV-irradiation influenced by e.g. starch gelatinization, whereas the slight decrease in the sample with $40 \%$ of Aloe vera may result from changing the gelatinized form to the retrograded one [30,31]. It may be affected by some photo-oxidation or photo-degradation processes occurring in a competitive way.

It should be mentioned that the ATR-FTIR analysis refers to the surface of the sample and allows the determination of the so-called short-range order on the molecular level, while the results obtained from the XRD method concern the entire sample and allow the relative crystallinity values specification as a long-range order [28]. The confirmation of trends in changes in the crystallinity degree of samples with varying Aloe content as well as those subject to UV radiation by means of these two different but complementary techniques becomes all more valuable and provides much information about changes taking place in the samples.

It is worth noticing that the strong absorption region between 900 and $1200 \mathrm{~cm}^{-1}$ is also characteristic of the chitosan saccharide structure [32]. According to literature data, the peaks at $850 \mathrm{~cm}^{-1}, 925 \mathrm{~cm}^{-1}$, and $995 \mathrm{~cm}^{-1}$ are
Table 1 Changes in carbonyl index $\left(\mathrm{I}_{\mathrm{C}=\mathrm{O}}\right)$, hydroxyl index $\left(\mathrm{I}_{\mathrm{O}-\mathrm{H}}\right), \mathrm{R}_{1}=\mathrm{I}_{(1150) /(994)}$ and $\mathrm{R}_{2}=\mathrm{I}_{(1040) /(1012)}$ ratios calculated for all the samples before and after 24-h UV-irradiation

\begin{tabular}{|c|c|c|c|c|c|c|c|c|}
\hline & \multicolumn{8}{|c|}{ Time of UV irradiation (h) } \\
\hline & \multicolumn{2}{|c|}{$\mathrm{I}_{\mathrm{C}=\mathrm{O}}$} & \multicolumn{2}{|l|}{$\mathrm{I}_{\mathrm{O}-\mathrm{H}}$} & \multicolumn{2}{|c|}{$\mathrm{R}_{1}=\mathrm{I}_{(1150) /(994)}$} & \multicolumn{2}{|c|}{$\mathrm{R}_{2}=\mathrm{I}_{(1040) /(1012)}$} \\
\hline & $0 \mathrm{~h}$ & $24 \mathrm{~h}$ & $0 \mathrm{~h}$ & $24 \mathrm{~h}$ & $0 \mathrm{~h}$ & $24 \mathrm{~h}$ & $0 \mathrm{~h}$ & $24 \mathrm{~h}$ \\
\hline $\mathrm{SC}$ & 0 & $0.09876(9.8 \%)$ & 3.44 & $1.9691(-42.76 \%)$ & 0.3566 & 0.3396 & 0.5488 & 0.6954 \\
\hline SCA 10 & 0 & $0.1026(10.26 \%)$ & 3.00 & $2.01225(-32.92 \%)$ & 0.3477 & 0.3476 & 0,5393 & 0.5950 \\
\hline SCA 20 & 0 & $0.1009(10.09 \%)$ & 3.98 & $2.1102(-46.98 \%)$ & 0.3555 & 0.3498 & 0.5021 & 0.5428 \\
\hline SCA 30 & 0 & $0.1552(15.52 \%)$ & 3.41 & $1.7967(-47.31 \%)$ & 0.3435 & 0.3380 & 0.5160 & 0.5547 \\
\hline SCA 40 & 0 & $0.1498(14.98 \%)$ & 3.62 & $1.6060(-55.64 \%)$ & 0.3559 & 0.3456 & 0.5491 & 0.5205 \\
\hline SCA 50 & 0 & $0.1525(15.25 \%)$ & 3.91 & $2.11455(-45.92 \%)$ & 0.2526 & 0.2755 & 0.4426 & 0.4977 \\
\hline
\end{tabular}


Fig. 3 ATR-FTIR spectra of starch/chitosan sample with $50 \%$ (ww) of Aloe v. gel (SCA 50) before (red line) and after 5- (green) and 24-h (blue) UV-irradiation (a spectra range $1200-700 \mathrm{~cm}^{-1}$, b spectra range $1800-1200 \mathrm{~cm}^{-1}$ )
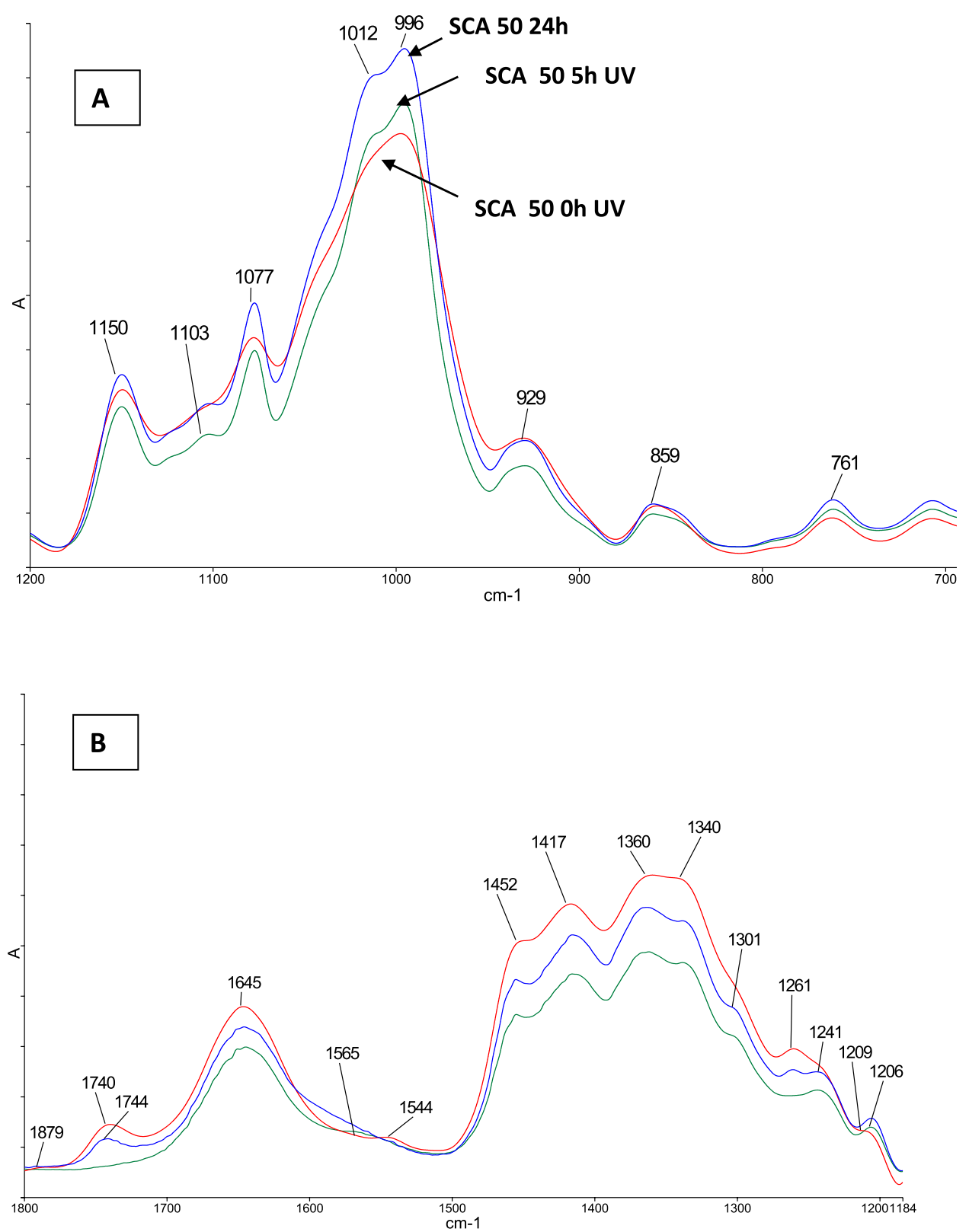

related to the vibration of the $\mathrm{C}-\mathrm{C}$ skeleton. Then, the maxima at about $1045 \mathrm{~cm}^{-1}$ and $1117 \mathrm{~cm}^{-1}$ are associated with the presence of the $\mathrm{C}-\mathrm{O}$ stretching vibration of $\mathrm{C}-\mathrm{C}$ linkage, and with the $\mathrm{C}-\mathrm{O}$ vibration in glucoside ring, respectively $[9,14]$. Moreover, glycerol shows the typical absorption maxima located in $800 \mathrm{~cm}^{-1}-1150 \mathrm{~cm}^{-1}$ spectral range, which correspond to the $\mathrm{C}-\mathrm{C}$ vibrations and $\mathrm{C}-\mathrm{O}$ linkages.

The low intensity bands in the range of $2800-3000 \mathrm{~cm}^{-1}$ are associated with stretching the symmetric $\left(2939 \mathrm{~cm}^{-1}\right)$ and asymmetric $\left(2868 \mathrm{~cm}^{-1}\right)$ methylene $\left(\mathrm{CH}_{2}\right)$ vibration in each component. Therefore, these bands are attributed to the presence of long aliphatic chains in Aloe vera $(-\mathrm{CH})$ and $-\mathrm{CH}_{2}$ and $-\mathrm{CH}_{3}$ stretching vibrations in starch and chitosan.
The broad absorption band of low intensity with the maximum at $859 \mathrm{~cm}^{-1}$ is considered to arise from the outof plane $\mathrm{C}-\mathrm{H}$ deformation of the mannose or pyranose ring in Aloe [26].

The mode band of free water is also noticeable at about $1645 \mathrm{~cm}^{-1}$. It confirms the high hydration of the samples. It may also correspond to $\mathrm{C}=\mathrm{O}$ stretching vibrations, which would mean that chitosan is not completely deacetylated [32].

According to literature reports, the peak at $1590 \mathrm{~cm}^{-1}$ which is characteristic of amide I (NH bending vibrations) should be noticeable for samples prepared without glycerin plasticizer. The appearance of this arm results from the presence of $-\mathrm{NH}_{3} \mathrm{OC}(=\mathrm{O}) \mathrm{CH}_{3}$ interactions between chitosan 
and acetic acid, and it disappears when glycerol is added during the film formulation [33]. When glycerol plasticizer is used, the reaction between glycerol molecules and acetic acid may occur and it leads to the displacement of the bound acetic acid from the chitosan macromolecules. As a consequence, an increase in the number of $-\mathrm{NH}_{2}$ groups is finally observed. It can be expected that these groups may interact by hydrogen bonding with the acceptor molecules available in this system, i.e. glycerol, chitosan (with its hydroxyl and amine groups), starch and Aloe vera polysaccharides. Such a conclusion may arise from the lack of band at $1560 \mathrm{~cm}^{-1}$ with its shoulder at $1590 \mathrm{~cm}^{-1}$ in the FTIR-ATR spectra of the sample without Aloe vera gel. However, incorporating this compound into the starch/chitosan matrix results in the appearance of the low intensity shoulder in spectral range $1565-1544 \mathrm{~cm}^{-1}$, which is attributed to $\mathrm{C}=\mathrm{C}$ bonds in carvone as well as vinyl ether in aloin present in Aloe vera gel [26, 34]. Another amide band present in chitosan (amide III) appears on the IR-spectra at $1317 \mathrm{~cm}^{-1}$ [32].

The main absorption peak of pure chitosan, which is observed at $1645 \mathrm{~cm}^{-1}$ is attributed to $\mathrm{C}=\mathrm{O}$ stretching (amide I); but the bands at $1558 \mathrm{~cm}^{-1}$, assigned to $\mathrm{N}-\mathrm{H}$ bending (amide II), and at $1382 \mathrm{~cm}^{-1}$, assigned C-N stretching (amide III) are not observed in the spectra of the mixtures. The peak broadening at $1050 \mathrm{~cm}^{-1}$ is assigned to $\mathrm{C}-\mathrm{O}$ stretching, and the broad band above $3000 \mathrm{~cm}^{-1}$ corresponds to $\mathrm{O}-\mathrm{H}$ and $\mathrm{N}-\mathrm{H}$ bonds [35].

Figure 3 shows the FTIR-ATR spectra of samples with $50 \%$ of Aloe vera gel before and after 5- to 24-h UV-irradiation in the selected spectral ranges. Shorter times of UV irradiation also influenced the reduction of $\mathrm{O}-\mathrm{H}$ stretching, which was determined on the basis of changes in intensities at the maximum of $\mathrm{O}-\mathrm{H}$ bands at $3000-3700 \mathrm{~cm}^{-1}$ spectral range. It is a result of loss of bounded water or some oxidation reaction of the blends constituents, i.e. oxidation of anthraquinones present in Aloe vera [26].

A similar trend persists for samples with the Aloe vera content from 0 to $40 \%$ and UV-exposition up to $24 \mathrm{~h}$. Some differences are noticed in the sample with the highest amount of AV gel (50\%) after $24 \mathrm{~h}$ of irradiation, where the increase in the $-\mathrm{OH}$ band intensity was observed. Concequently, it leads to the formation of less ordered structures caused by the conformational transformation of native biopolymers. The small intensity of $\mathrm{C}-\mathrm{O}$ and $\mathrm{C}-\mathrm{OH}$ bands in the spectral range of $950-1100 \mathrm{~cm}^{-1}$ after $\mathrm{UV}$-irradiation confirms the presence of highly stable monosaccharide units derived both from Aloe (e.g. galactose, glucan) as well as chitosan and starch.

The amount of incorporated Aloe vera gel (up to 50\%) does not influence the $\mathrm{O}-\mathrm{H}$ bands intensities; however, $24 \mathrm{~h}$ of UV-irradiation caused a decrease in intensities (up to $\sim 55 \%$ ) in the $\mathrm{O}-\mathrm{H}$ spectral range. The hydroxyl index $\left(\mathrm{I}_{\mathrm{O}-\mathrm{H}}\right)$ was determined according to the formula: $\mathrm{I}_{\mathrm{O}-\mathrm{H}} / \mathrm{I}_{\mathrm{C}-\mathrm{H}}$, where the height of O-H $\left(3600 \mathrm{~cm}^{-1}\right)$ and C-H $\left(2922 \mathrm{~cm}^{-1}\right)$ bands (measured from baseline) was used. It was noticed that this parameter increased after UV irradiation for all the samples. However, these changes (increase) strongly depend on the AV concentration in the sample-the more Aloe vera gel in the starch matrix the fewer hydroxyl groups formed after irradiation. The highest $\mathrm{O}-\mathrm{H}$ percentage increase was noticed for the pure starch/chitosan sample (Table 1).

Simultaneously, the carbonyl bands appear on the spectra just after shorter irradiation time, and this trend is similar for all the samples with AV gel. However, the lowest change in carbonyl index $\left(\mathrm{I}_{\mathrm{C}=\mathrm{O}}\right)$ (calculated as a ratio between intensities in the maximum of $\mathrm{C}=\mathrm{O}$ band (at $1740 \mathrm{~cm}^{-1}$ ) to $\mathrm{C}-\mathrm{H}\left(2922 \mathrm{~cm}^{-1}\right)$ after UV-irradiation was established for the sample without Aloe vera gel and with $10-20 \%$ of AV $\left(\mathrm{I}_{\mathrm{C}=\mathrm{O}} \sim 10 \%\right.$ ), and it increased (up to $\sim 15 \%$ ) for samples with a higher amount of this compound (30\% to 50\%). This trend is maintained in the case of the samples irradiated for $24 \mathrm{~h}$.

\section{XRD Studies}

The X-ray diffraction patterns characteristic for native potato starch and starch-based films with glycerol, chitosan, and Aloe vera gel are presented in Fig. 4. Native potato starch as well as films with chitosan and Aloe vera shows the stronger reflections at $2 \theta \approx 17,20,22,24^{\circ}$, which are characteristic of B-type crystallities, whereas a weak and broad peak at $15^{\circ}$ attributed to A -type crystallities is also present.[30, 36 ]. Moreover, the peak observed at $2 \theta \approx 5^{\circ}$ corresponds to B-structure starch. However, it can also be associated with the interactions between glycerol and short, external amylopectin chains which are presented in starch. Additionally, the marked peak at $2 \theta \approx 19.5^{\circ}$ is present and, according to literature data, it corresponds to the new, crystalline structure of the stable single V-type chain formed as a result of interactions between glycerol and linear amylose in starch.[19].

Although the diffractograms of all the samples look similar, there are some differences observed. Starch/chitosan/ AV samples exhibit some slight changes in intensities and locations of XRD signals, especially a decrease in the peaks intensity at 19.5 and $22^{\circ}$ compared with those for native starch and starch/chitosan films. The broadening of characteristic XRD patterns indicates that some interaction between components has occurred. According to literature, the small crystal size as well as presence of many lattice defects are responsible for XRD pattern broadening [37]. The sample with $30 \% \mathrm{AV}$ where the increase in these intensities is observed constitutes the exception. One can suspect that some interaction between glycerol and amylose might be limited by amylose cross-linking.

The crystalline structures of potato starch are formed by branched-amylopectin macromolecules, while the linear amylose macromolecules form an amorphous phase. It is 
Fig. 4 XRD spectra of starch, starch/chitosan (SC) and starch/ chitosan $/ 50 \%$ Aloe vera gel (SCA 50) films

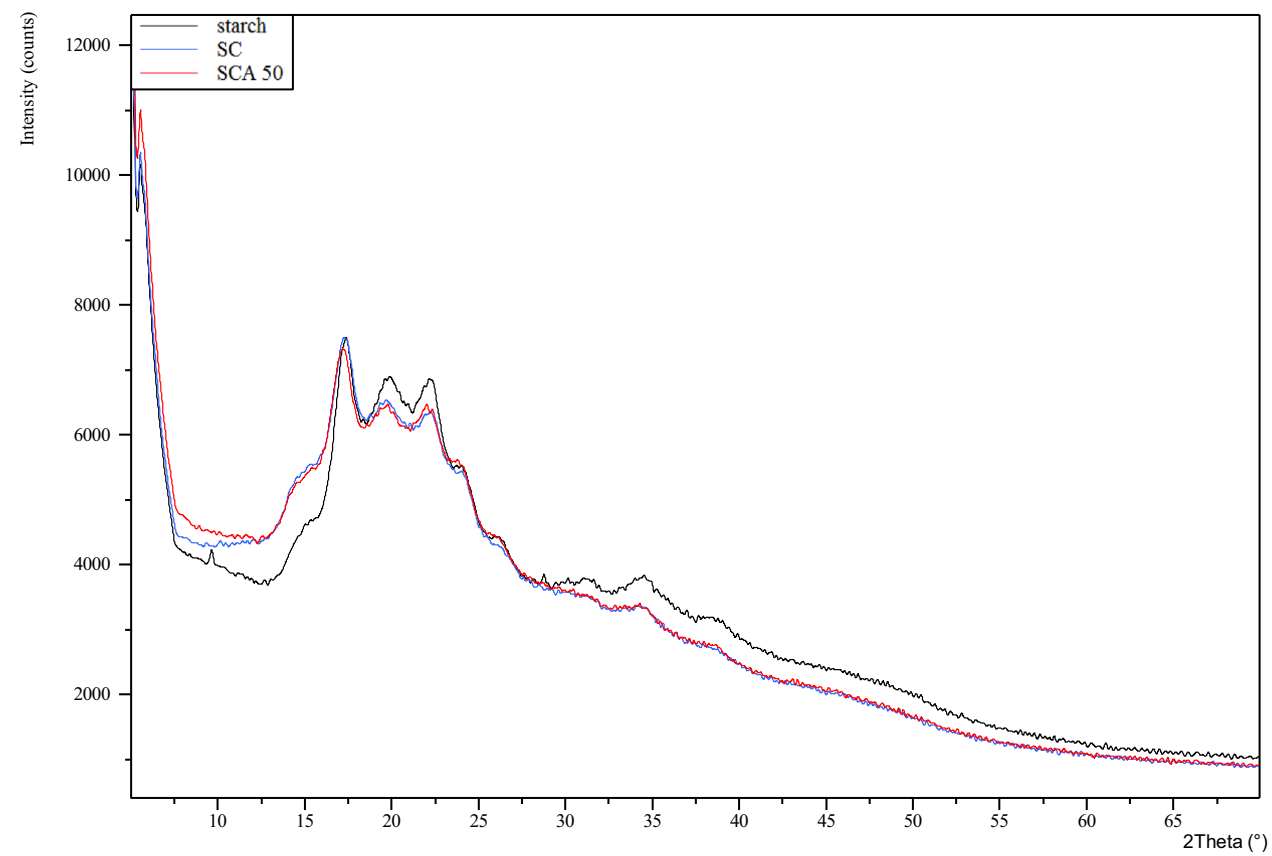

worth mentioning that the peak breadth is inversely proportional to the crystallite size in the polymer and indicates the amorphous or crystalline nature of starch [29, 38].

A further analysis confirmed some differences in the relative crystallinity degree $\left(\mathrm{X}_{\mathrm{c}}\right)$ noticed for all the samples (Tab. 2).

Native potato starch powder is characterized by the lowest $\mathrm{X}_{\mathrm{c}}$ values $\left(\mathrm{X}_{\mathrm{c}}=14.4 \%\right)$, but the glycerin and chitosan addition to the starch matrix significantly increases its crystallinity to $X_{c}=15.95 \%$ and $X_{c}=29.36 \%$, respectively. It may be influenced by some cleavage of the starch chains situated in the amorphous region and re-crystallization leading to conformational changes.

Although the addition of Aloe vera gel influenced the reduction of the crystallinity degree in comparison to the degree of the starch/chitosan sample, but the correlation between the AV concentration and $X_{c}$ increase is distinct.
The relative crystallinity increases with a higher amount of Aloe vera gel in a sample. One can expect some interactions (e.g. hydrogen bonding) between amylose-amylopectin, amylopectin-amylopectin [2], and/or its reaction with other components (chitosan and Aloe vera) during the film formation, which contributes to the occurrence of such trends in starch ordering. AV gel may promote starch cross-linking which results in the alignment of carbohydrate polysaccharide chains, and leads to converting, the amorphous to crystalline state. Similar results were describe by T. J. Gutierez and K. Alvarez [19].

Using the value for FWHM of the signal at $2 \theta=15,1^{\circ}$ and $22,25^{\circ}$ assigned to (140) and (113) crystallographic plane reflection in the XRD diffractogram of starch, the size of crystallite was calculated according to DebyeScherer equation (Eq. 2).

Table 2 Crystallinity index (Xc, \%), crystallite size (L, nm) and d-spacing values $(\mathrm{d}, \mathrm{nm})$ for potato starch powder, starch glycerol film and its mixture with chitosan and Aloe vera gel (from 10 to $50 \%$ ) before and after 24-h UV-irradiation

\begin{tabular}{|c|c|c|c|c|c|c|c|c|c|c|}
\hline \multirow[t]{3}{*}{ Sample formulation } & \multicolumn{2}{|l|}{$X_{c}, \%$} & \multicolumn{4}{|c|}{ Crystallite size $\mathrm{L}, \mathrm{nm}$} & \multicolumn{4}{|c|}{ d-Spacing, nm } \\
\hline & \multirow[t]{2}{*}{$0 \mathrm{~h} \mathrm{UV}$} & \multirow[t]{2}{*}{24 h UV } & \multicolumn{2}{|l|}{$0 \mathrm{~h} \mathrm{UV}$} & \multicolumn{2}{|c|}{$24 \mathrm{~h} \mathrm{UV}$} & \multicolumn{2}{|l|}{$0 \mathrm{~h} \mathrm{UV}$} & \multicolumn{2}{|c|}{$24 \mathrm{~h} \mathrm{UV}$} \\
\hline & & & $2 \theta=5^{\circ}$ & $2 \theta=24^{\circ}$ & $2 \theta=5^{\circ}$ & $2 \theta=24^{\circ}$ & $2 \theta=5^{\circ}$ & $2 \theta=24^{\circ}$ & $2 \theta=5^{\circ}$ & $2 \theta=24^{\circ}$ \\
\hline $\mathrm{SC}$ & 29.36 & 34.60 & 15.2 & 10.3 & 31.2 & 14.5 & 1.5683 & 0.3706 & 1.4930 & 0.3674 \\
\hline SCA 10 & 25.63 & 22.00 & 9.3 & 6.7 & 15.3 & 4.6 & 1.5494 & 0.3628 & 1.5355 & 0.3674 \\
\hline SCA 20 & 27.39 & 22.45 & 8.9 & 6.4 & 8.8 & 10 & 1.5684 & 0.3695 & 1.5340 & 0.3659 \\
\hline SCA 30 & 28.76 & 22.26 & - & 6.0 & 13.1 & 9.7 & 1.5973 & 0.3636 & 1.5383 & 0.3640 \\
\hline SCA 40 & 30.13 & 38.28 & 9.2 & 11.5 & 14.0 & - & 1.5443 & 0.3690 & 1.5369 & 0.3702 \\
\hline SCA 50 & 33.71 & 25.00 & 10.8 & 11.5 & 13.3 & 11.2 & 1.5684 & 0.3770 & 1.5341 & 0.3682 \\
\hline
\end{tabular}


$\mathrm{D}=0.9 \lambda / \beta \cos \theta$

where: $\mathrm{D}$ is the particle diameter size, $\lambda$ is the wavelength of X-Ray $(0.15059 \mathrm{~nm}) ; \theta$ is the diffraction angle, $\beta$ is the full width at a half maximum (FWHM).

The crystallite sizes (L) are $26.8 \mathrm{~nm}$ for native potato starch, $5.8 \mathrm{~nm}$ for starch/glycerol film, $15.2 \mathrm{~nm}$ for starch/ chitosan (SC), and $10.8 \mathrm{~nm}$ for starch/chitosan/AV 50\% (SCA 50) (at $2 \theta=15^{\circ}$ ); and $27 \mathrm{~nm}$ for native potato starch, $4.6 \mathrm{~nm}$ for starch/glycerol film, $10.3 \mathrm{~nm}$ for starch/chitosan, and $11.5 \mathrm{~nm}$ for starch/chitosan/AV 50\% (at $2 \theta=24^{\circ}$ ). The crystallite size $(\mathrm{L})$ values are clearly higher for native potato powder and decrease after glycerol, chitosan and AV addition. However, this change is much greater for starch/glicerol film. The addition of Aloe vera gel promotes some irregular changes in the sizes of crystallites. Thus, its concentration does not allow defining a close relationship. Nevertheless, the incorporation of Aloe gel to the starch/chitosan film evidently reduced the measured crystallite size. The lattice d-spacing values for all the samples change slightly. Both, the mixture composition as well as its irradiation time remain almost without influence on this parameter. It suggests that the interaction between the plasticizer/starch/chitosan and/or Aloe vera were not definite and strong; thus, potato starch does not undergo any remarkable structural changes after Aloe vera gel and/or chitosan incorporation. An analogous result was described for a sample of Cotton Woven Fabric modified with chitosan and AV gel [18].

However, changes in $X_{c}$ and the crystallite size $(L, n m)$ leave no doubt that the influence of composition on the sample properties is obvious. Photo-irradiation caused the decrease in the crystallinity degree $\left(\mathrm{X}_{\mathrm{c}}\right)$ and increase in the crystallite size in all the analyzed samples containing Aloe vera gel (with two exceptions: $40 \%$ and $10 \%$ ), whereas the crystallinity degree of starch/chitosan blend became higher after UV-irradiation. It probably results from some crosslinking reactions which may be due to hydrogen bonding between the component of blends.

The changes in crystallinity and crystallite size can significantly influence the mechanical or physico-chemical properties of the obtained composites [39].

XRD patterns are very sensitive to water content, so the increase in moisture content in polymeric materials may affect the decrease in its crystallinity [38].

The results obtained by the XRD method, due to which crystallinity degree, understood as a long-range order, was determined and the drop of $X_{c}$ values was noticed (Table 2), are consistent with the FTIR-ATR results.

\subsection{Thermal Properties}

Thermal properties are decisive for the possibility of processing polymeric materials on an industrial scale. Processing with the use of extruders and industrial injection molding machines requires high temperature, hence knowledge of the thermal resistance and stability of polymers in such systems is of particular importance.

Thermogravimetric measurements were performed to establish the thermal stability of starch/chitosan films and to investigate the influence of Aloe vera gel incorporation and its concentration in the polymer matrix. Determining the thermal stability and temperature values of thermal degradation is very important. Figure 5 gives a combined representation of DTG curves obtained for starch, starch/chitosan and
Fig. 5 Derivative of weight loss (DTG) of starch, starch/chitosan and starch/chitosan with Aloe vera gel $(10-50 \% \mathrm{ww})$ films

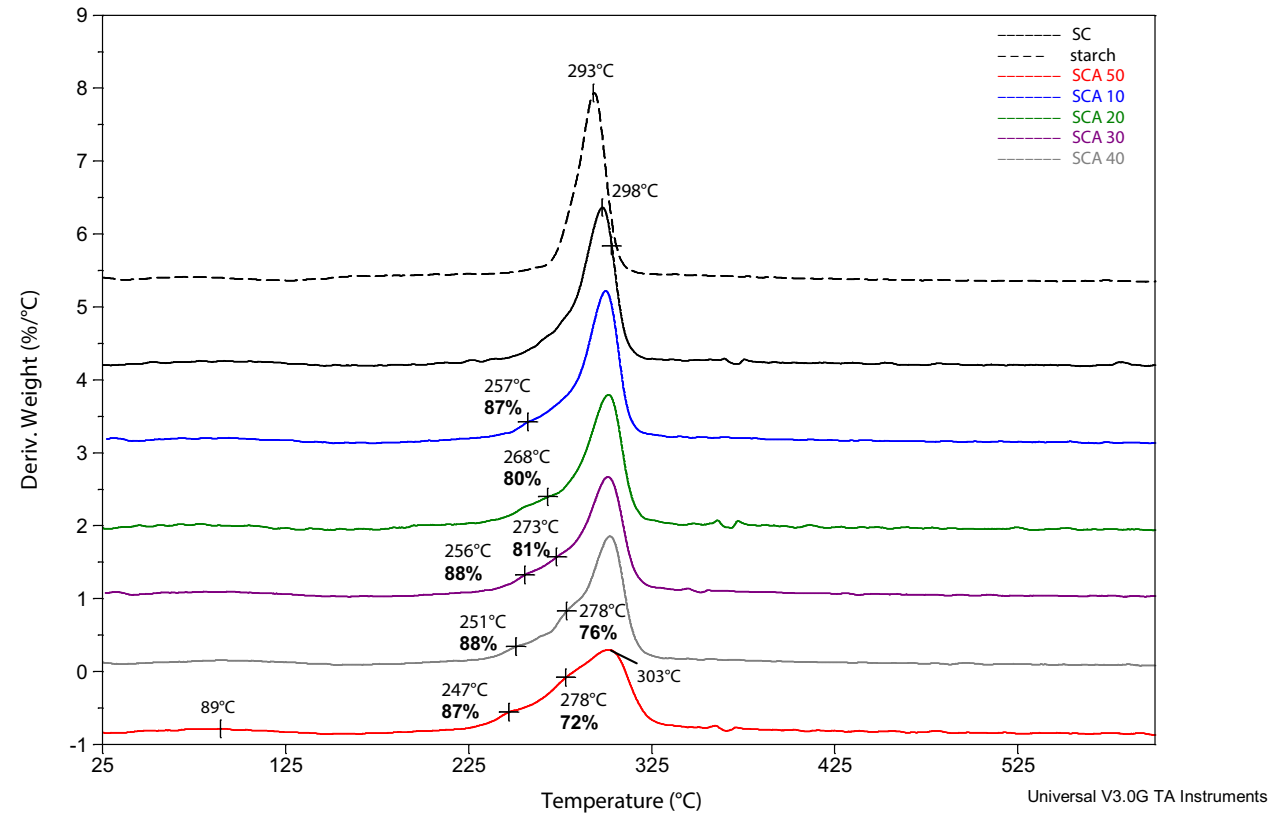


starch/chitosan/AV blends. The thermograms confirmed the main one-stage decomposition process preceded by the initial stage (at about $70-100^{\circ} \mathrm{C}$ ) of moisture and the volatiles loss and small mass reduction.

The obtained results indicate, the temperature changes at this stage depend on the mixture composition. Moisture is most quickly released from pure starch films $\left(\sim 70{ }^{\circ} \mathrm{C}\right)$, then from films containing chitosan $\left(\sim 78^{\circ} \mathrm{C}\right)$, and finally from blends with the higher Aloe addition $\left(\sim 91-95^{\circ} \mathrm{C}\right)$. The observed temperature shift can indicate that some chains reorganization or new bonds formation occur between biopolymers in films which effectively trap moisture within the matrix and limit its evaporation. The main stage of decomposition (with $\mathrm{T}_{\max }$ at $293-302{ }^{\circ} \mathrm{C}$ ) is associated with thermal depolymerization and pyrolytic degradation of the film components: chitosan as well as amylose and amylopectin in starch (glyosidic bonds are broken and mono- and disaccharide are formed). According to literature data, the thermal decomposition of pure chitosan occurs at a temperature of about $330^{\circ} \mathrm{C}$, which is higher than the values obtained for mixtures of starch/chitosan (SC). The presence of a single peak on SC blends thermograms is probably due to (i) the interactions and some new bonds formation leading to cross-linking reactions between starch and chitosan in blends, and (ii) the formation of a single-phase system and its consequences $[9,10,19,40]$. However, the occurrence of peak broadening (SCA 10) and presence of peaks that are not separated (with one or two additional maxima) are observed on thermograms for samples with the addition of a higher amount of Aloe vera gel (Table 3).

The first of the mentioned maxima is shifted toward lower temperature values, whereas the next one is moved towards higher temperature values when Aloe vera concentration in the polymer matrix increases. Therefore, the initial temperatures $\left[\mathrm{T}_{0}\right]$ of the main stage decomposition are shifted from $249{ }^{\circ} \mathrm{C}$ for the starch/glycerol blend to $227^{\circ} \mathrm{C}$ for the chitosan/starch/glycerol sample and to $219^{\circ} \mathrm{C}$ for the sample with $50 \%$ Aloe vera content. The obtained result depends on the Aloe vera gel concentration in blends. This may even indicate some phase separation after AV gel incorporation. A slight broadering on the DTG peak may indicate the presence of two almost completely overlapping thermal processes, whereas the elongated peak end may indicate strong adsorption of gaseous decomposition products on the surface of the newly formed phase.

Moreover, one can observe that temperatures at the maximum rate of thermal degradation $\left(\mathrm{T}_{\max },{ }^{\circ} \mathrm{C}\right)$ are shifted from $293{ }^{\circ} \mathrm{C}$ (for starch film) to $298^{\circ} \mathrm{C}$ (for starch/chitosan film) and to $302{ }^{\circ} \mathrm{C}$ (for the sample with $50 \%$ Aloe vera gel). Despite the fact that the maximum rate of decomposition occurs with a delay, the temperature of degradation onset $\left(\mathrm{T}_{0},{ }^{\circ} \mathrm{C}\right)$ is already shifted to lower temperature values. It may result from some cross-linking reactions occurring between the amorphous region of starch and natural agents entering the matrix. The changes in the starch thermal resistance with the addition of chitosan or chitosan and Aloe vera gel can be explained by the effective contribution of these compounds, their intercalations and agglomerations inside the starch matrix. New intermolecular hydrogen bonding can form and, in consequence, it promotes an increase in crystallinity verified with XRD and ATR-FTIR analyses.

To sum up, Aloe vera gel as well as chitosan influenced the thermal resistance of starch-based samples and significantly delayed the decomposition maximum in comparison to systems of non-modified pure starch film.

Further temperature increase affects the release of volatile compounds only (e.g. $\mathrm{CO}_{2}, \mathrm{CO}$ ) and the complete decomposition of the samples occurs at $500{ }^{\circ} \mathrm{C}$.

The influence of UV-radiation on the temperature of thermal decomposition is relevant (Fig. 6).

Both, the temperature of the first stage of degradation ( $\mathrm{T}_{\max }$ loss of moisture) as well as the second one ( $\mathrm{T}_{\max }$ of the sample decomposition) are shifted into higher values in comparison to non-irradiated samples (Table 4).

UV-light may promote photo-crosslinking processes which strengthen the structures through, for example, creating covalent or hydrogen bonds. Such behavior is also reflected in the decrease in the crystallinity degree of
Table 3 Thermal parameters: Temperature of degradation onset $\left(\mathrm{T}_{0},{ }^{\circ} \mathrm{C}\right)$, temperature of maximum degradation rate (Tmax, ${ }^{\circ} \mathrm{C}$ ), and weight loss $(\Delta \mathrm{m}, \%)$ determined for no irradiated samples

\begin{tabular}{|c|c|c|c|c|c|}
\hline \multirow[t]{2}{*}{ Sample formulation } & \multicolumn{2}{|c|}{$\begin{array}{l}\text { I stage (loss of moisture) } \\
\left(0-150{ }^{\circ} \mathrm{C}\right)\end{array}$} & \multirow[b]{2}{*}{$\mathrm{T}_{0}\left({ }^{\circ} \mathrm{C}\right)$} & \multicolumn{2}{|c|}{$\begin{array}{l}\text { II stage (sample docomposition) } \\
\left(150-330^{\circ} \mathrm{C}\right)\end{array}$} \\
\hline & $\operatorname{TmaxI}\left({ }^{\circ} \mathrm{C}\right)$ & $\begin{array}{l}\text { Weight loss } \\
\Delta \mathrm{m}_{\mathrm{I}}(\%)\end{array}$ & & $\operatorname{TmaxII}\left({ }^{\circ} \mathrm{C}\right)$ & $\begin{array}{l}\text { Weight loss } \\
\Delta \mathrm{m}_{\mathrm{II}}(\%)\end{array}$ \\
\hline S & 70 & 6.1 & 249 & --293 & 54 \\
\hline $\mathrm{SC}$ & 78 & 5.8 & 227 & --298 & 64 \\
\hline SCA 10 & 94 & 6.7 & 215 & $-257 ; 300$ & 64 \\
\hline SCA 20 & 78 & 6.4 & 227 & $256 ; 268 ; 301$ & 69 \\
\hline SCA 30 & 95 & 6.1 & 226 & $256 ; 273 ; 301$ & 61 \\
\hline SCA 40 & 90 & 6.3 & 223 & $251 ; 278 ; 302$ & 64 \\
\hline SCA 50 & 91 & 6.2 & 219 & $247 ; 278 ; 303$ & 66 \\
\hline
\end{tabular}


Fig. 6 DTG curves of the samples without Aloe vera gel (SC) and with 50\% Aloe vera gel concentration (SCA 50), before and after 24-h UV-irradiation

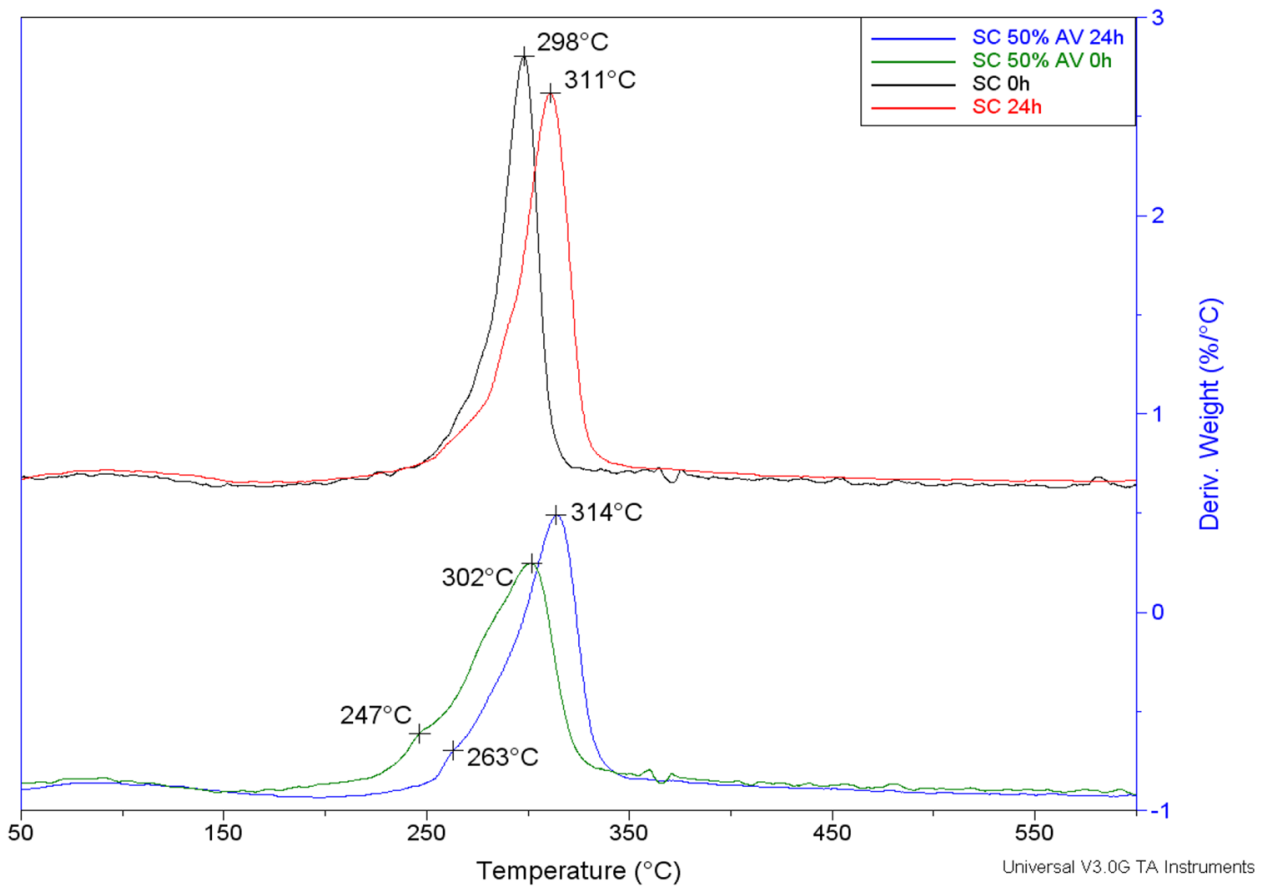

\begin{tabular}{|c|c|c|c|c|c|}
\hline \multirow[t]{2}{*}{ Sample formulation } & \multicolumn{2}{|c|}{$\begin{array}{l}\text { I stage (loss of moisture) } \\
\left(0-150{ }^{\circ} \mathrm{C}\right)\end{array}$} & \multirow[b]{2}{*}{$\mathrm{T}_{0}\left({ }^{\circ} \mathrm{C}\right)$} & \multicolumn{2}{|c|}{$\begin{array}{l}\text { II stage (sample docomposi- } \\
\text { tion) }\left(150-330^{\circ} \mathrm{C}\right)\end{array}$} \\
\hline & $\operatorname{TmaxI}\left({ }^{\circ} \mathrm{C}\right)$ & $\begin{array}{l}\text { Weight loss } \\
\Delta \mathrm{m}_{\mathrm{I}}(\%)\end{array}$ & & $\operatorname{Tmax} I I\left({ }^{\circ} \mathrm{C}\right)$ & $\begin{array}{l}\text { Weight loss } \\
\Delta \mathrm{m}_{\mathrm{II}}(\%)\end{array}$ \\
\hline$S$ & - & - & - & - & - \\
\hline $\mathrm{SC}$ & 92 & 6.0 & 200 & -311 & 68.7 \\
\hline SCA 10 & 113 & 6.7 & 202 & -313 & 63.8 \\
\hline SCA 20 & 111 & 7.7 & 214 & $258 ; 314$ & 63.8 \\
\hline SCA 30 & 109 & 7.3 & 200 & $258 ; 314$ & 64.3 \\
\hline SCA 40 & 108 & 6.4 & 200 & $291 ; 314$ & 66.3 \\
\hline SCA 50 & 97 & 7.9 & 210 & $263 ; 314$ & 61.8 \\
\hline
\end{tabular}

Table 4 Thermal parameters: Temperature of degradation onset $\left(\mathrm{T}_{0},{ }^{\circ} \mathrm{C}\right)$, temperature of maximum rate of degradation (Tmax, ${ }^{\circ} \mathrm{C}$ ), and weight loss $(\Delta \mathrm{m}, \%)$ determined for samples after 24-h UV-irradiation
UV-treated samples (determined on the basis of the XRD analysis).

\section{Contact Angle Measurements}

Contact angle measurements give the information about hydrophobicity or hydrophilicity of materials. This property is very important for the purpose of their application as packaging materials, especially in food industry, where the use of limited water permeability packaging is crucial to maintain the durability of food products [10]. Incorporating chitosan into the starch matrix has an impact on lowering free surface energy (IFT) value $\left[32.9 \mathrm{~mJ} / \mathrm{m}^{2}\right]$ as well as its polar component $\left[23 \mathrm{~mJ} / \mathrm{m}^{2}\right]$, and this combination seems to be the most hydrophobic one when compared to other samples. Thus, the addition of Aloe vera into biopolymer (starch/chitosan) films influenced the increase in the contact angle and calculated free surface energy IFT [mJ/ $\mathrm{m}^{2}$ ], which was also linearly correlated with the increase in Aloe concentration in the samples. Free surface energy reached the maximum value of $36.8 \mathrm{~mJ} / \mathrm{m}^{2}$ for the sample containing 50\% Aloe vera gel. As IFT remains at low (only a few percent) level for samples with higher concentration of Aloe vera gel, it confirms that the addition of AV gel to the starch/chitosan matrix leads to some increase in hydrophilicity. However, these changes are not expressive. Additionally, the observed increase in IFT values after $24 \mathrm{~h}-\mathrm{UV}$-irradiation confirms some rise in hydrophilicity which is induced by photo-oxidative degradation. These trends persist in the case of blends with Aloe vera; however, the percentage of IFT changes becomes significantly smaller with the increase in the AV gel concentration. The $50 \%$ addition of Aloe vera resulted in only $\sim 2 \mathrm{~mJ} / \mathrm{m}^{2}$ increase in the free surface energy value after 24 of UV-irradiation when compared to 
non-irradiated samples. In comparison to the above results, the change in the IFT value for the sample with $20 \%$ AV differs more significantly after $24 \mathrm{~h}$ of UV-exposition (Fig. 7). This result confirms the strong influence of not only Aloe vera but also the role of UV-radiation on the surface properties of starch films and their hydrophilic character.

It indicates that the incorporation of higher Aloe gel amount reduces the effect of UV-radiation on the starch/ chitosan sample. This may occur as a result of new chemical bonds formation between those biopolymers and Aloe vera components, which leads to higher resistance against UV-radiation.

\section{Atomic Force Microscopy (AFM)}

The AFM micrographs, which directly illustrate the film surface up to $10 \mathrm{~nm}$, are presented in Fig. 8 [41]. The aim of this research was to determine the influence of Aloe vera addition to a chitosan/starch blend and the UV- irradiation effect on the surface topography of the samples.

The AFM images reveal the samples morphology to be very rough, with numerous recesses that resemble steep hills. There are no significant visual differences in the topographies of starch/chitosan films with and without Aloe vera gel. However, the corrugations presented on the surface with a higher AV amount seem to be finer and more numerous, which can result from marked phase separation.

By comparing the images of samples surfaces before and after UV exposure, it can be concluded that there were no visible changes in the morphology of the tested objects.

However, the roughness parameters (RMS) of starch/ chitosan blends with different amounts of Aloe vera gel vary a in an irregular way and no clear dependence between these values and the samples composition is observed. Thus, the highest average arithmetic roughness $\left(\mathrm{R}_{\mathrm{a}}\right)$ and root-mean-square roughness $\left(\mathrm{R}_{\mathrm{q}}\right)$ values were obtained for the sample with maximal 50\% Aloe vera concentration (Table 5), which may suggest certain phase separation.

The trend of changes is different for the pure starch/ chitosan sample and with the sample containing Aloe vera gel. $R_{a}$ and $R_{q}$ of the blend without $A V$ are much lower and increase after UV-irradiation (Table 5). It is probably due to some photodegradation processes which occur mainly on the surface and may result in the morphological modification and changes in the crystal orderliness degree. The UV-radiation caused some etching processes, which may also lead to the increase in $R_{a}$ and $R_{q}$ parameter values. On the other hand, in the case of blends with $\mathrm{AV}$, a decrease in roughness parameters is evident after UV-treatment. There are also some correlations between the samples composition and the values of the roughness parameters after 5 and $24 \mathrm{~h}$ of irradiation. It is possible that some photo-degradation products could evaporate from samples surfaces leaving them smoother. Furthermore, it is clearly seen that samples with a higher Aloe vera amount (from 20 up to 50\%) seem to be less susceptible to UV-radiation when compared to samples with its lower concentration $(0-10 \%)$. However, this assumption stays in opposition to the $X_{c}$ results, in which the UV radiation influence was the highest on the sample with 50\% AV and comparable in the case of other samples with Aloe vera. Nevertheless, it confirms pure starch/chitosan film behavior.

These findings are consistent with previous results obtained from the FTIR-ATR spectra and surface free energy calculations received for the analyzed samples.
Fig. 7 Free surface energy IFT $[\mathrm{mJ} / \mathrm{m} 2]$ of starch/chitosan sample without Aloe vera $(0 \%)$ and with $10 \%, 20 \%, 30 \%$ and $50 \%$ ww of Aloe vera gel in starch/ chitosan blends. IFT measured for no-irradiated samples and after 5- and 24-h UV-irradiation
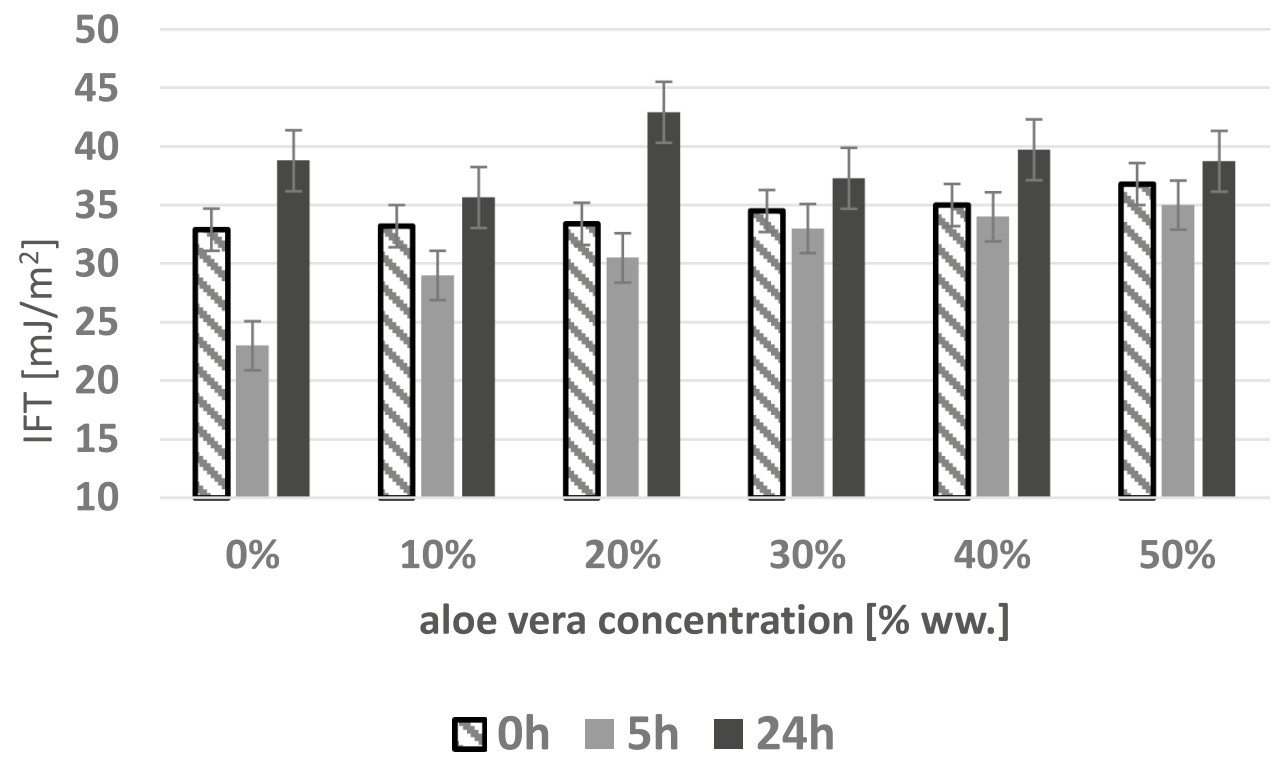


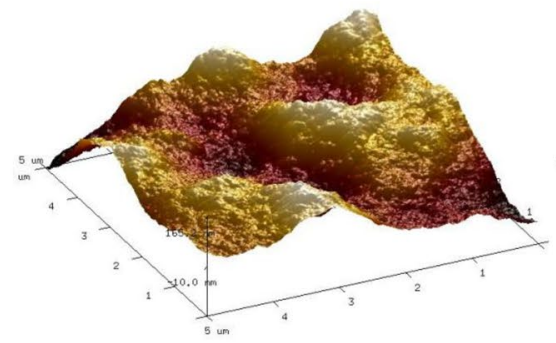

SC, OhUV

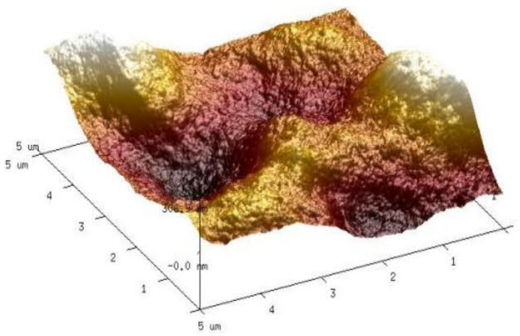

SCA 10, 0hUV

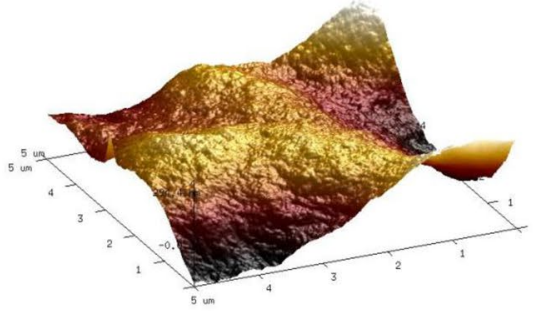

SC A 50, 0hUV

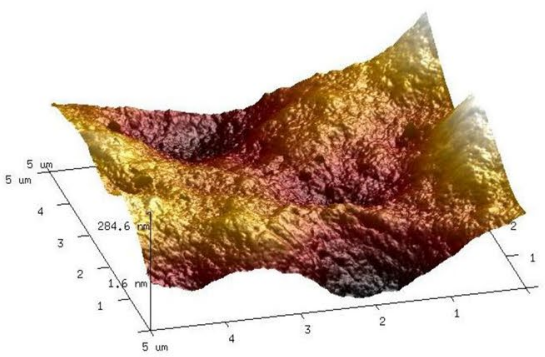

SC, 5hUV

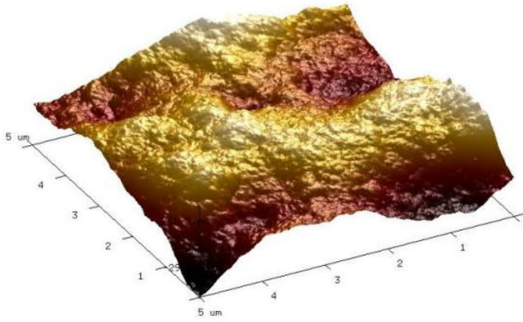

SCA 10, 5hUV

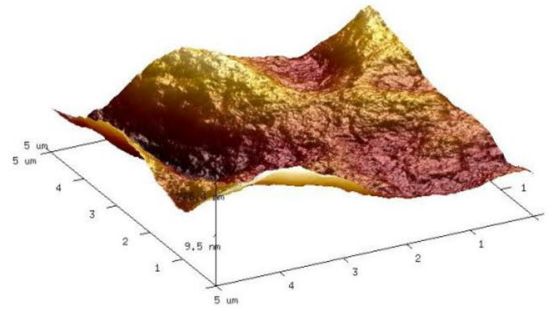

SCA 50, $5 \mathrm{hUV}$

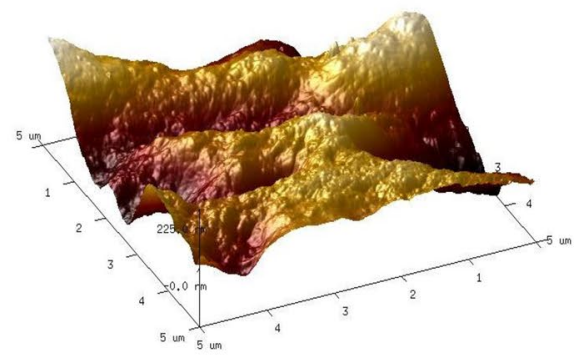

SC, $24 \mathrm{hUV}$

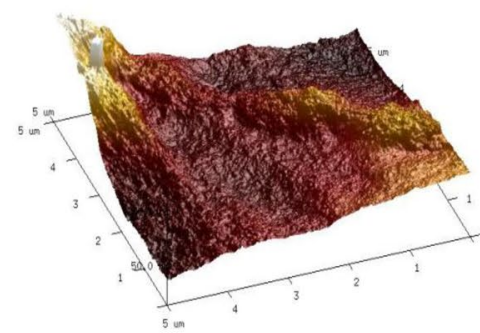

SCA 10, 24hUV

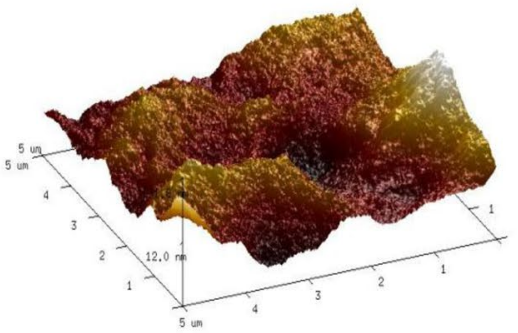

SCA 50, 24hUV

Fig. 8 AFM topographic surface images of starch/chitosan films without Aloe vera gel, and with 10 and 50\% AV, before and after 5- and 24-h UV irradiation

Table 5 Roughness parameters (RMS): Average roughness (Ra) and root-mean-square roughness $(\mathrm{Rq})$ of starch/ chitosan samples with $0-50 \%$ of Aloe Vera gel concentration. Samples before and after 5- and 24-h UV-irradiation

\begin{tabular}{|c|c|c|c|c|c|c|}
\hline \multirow[t]{3}{*}{ Sample formulation } & \multicolumn{3}{|c|}{$\mathrm{R}_{\mathrm{a}}(\mathrm{nm})$} & \multicolumn{3}{|c|}{$\mathrm{R}_{\mathrm{q}}(\mathrm{nm})$} \\
\hline & \multicolumn{3}{|c|}{ Irradiation time $(\mathrm{h})$} & \multicolumn{3}{|c|}{ Irradiation time $(\mathrm{h})$} \\
\hline & $0 \mathrm{~h}$ & $5 \mathrm{~h}$ & $24 \mathrm{~h}$ & $0 \mathrm{~h}$ & $5 \mathrm{~h}$ & $24 \mathrm{~h}$ \\
\hline $\mathrm{SC}$ & 43.9 & 60.2 & 87.2 & 60.2 & 76.6 & 114.5 \\
\hline SCA 10 & 80.0 & 63.9 & 39.4 & 101.0 & 76.2 & 51.0 \\
\hline SCA 20 & 65.1 & 59.8 & 58.0 & 78.9 & 87.4 & 70.2 \\
\hline SCA 30 & 51.6 & 43.6 & 46.0 & 63.0 & 54.7 & 64.2 \\
\hline SCA 40 & 52.1 & 41.6 & 40.0 & 65.9 & 52.3 & 51.0 \\
\hline SCA 50 & 94.2 & 75.4 & 23.0 & 117.8 & 94.2 & 29.7 \\
\hline
\end{tabular}




\section{Microbiological Analysis}

A microbiological test was conducted on two representative starch/chitosan samples containing the lowest (10\%) and the highest $(50 \%)$ Aloe vera gel concentrations. The susceptibility of films to microbial activity was assessed on the basis of visual assessment and mass changes (Figs. 9, $10,11,12$ \& 13).

In the both samples tested, after the first week of incubation, the mycelium coated the film significantly, covering
Fig. 9 Starch/chitosan/10\% AV film (SCA 10) Photo (a); and Starch/chitosan $/ 50 \%$ AV gel film (SCA 50) Photo (b)
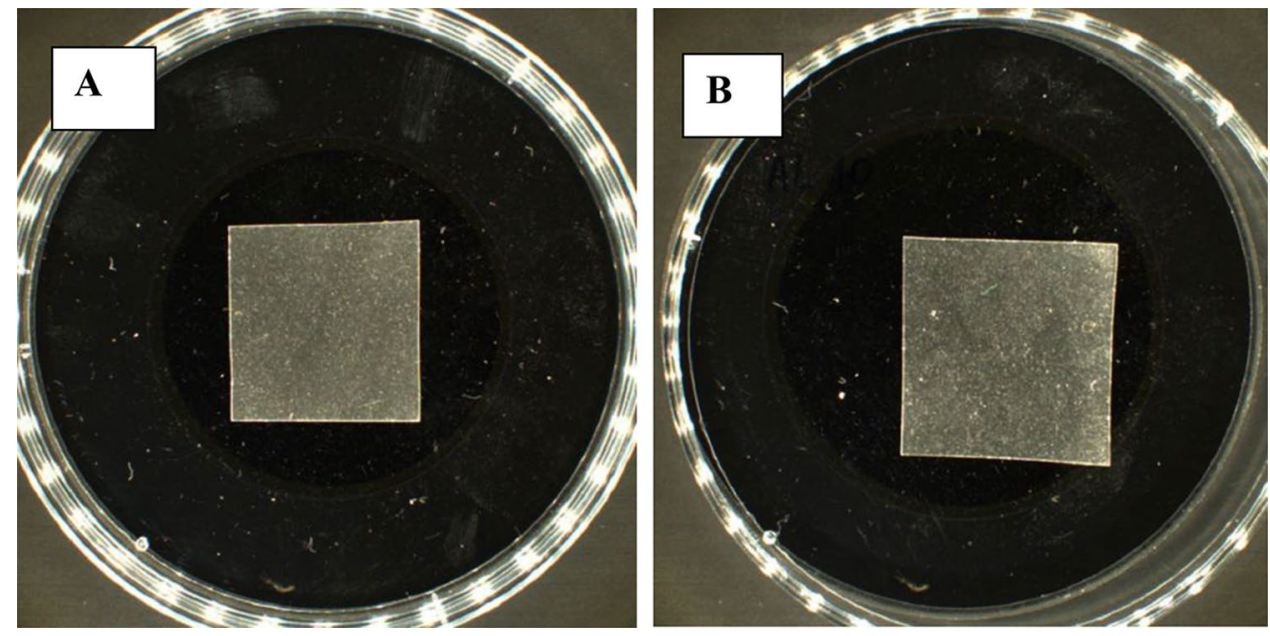

Fig. 10 SCA 10 inoculated with Bacillus sp. (a) and Fusarium culmorum (b) (a minimal medium amount for bacteria growing, b minimal medium amount for mushroom growing) after 2 weeks of incubation
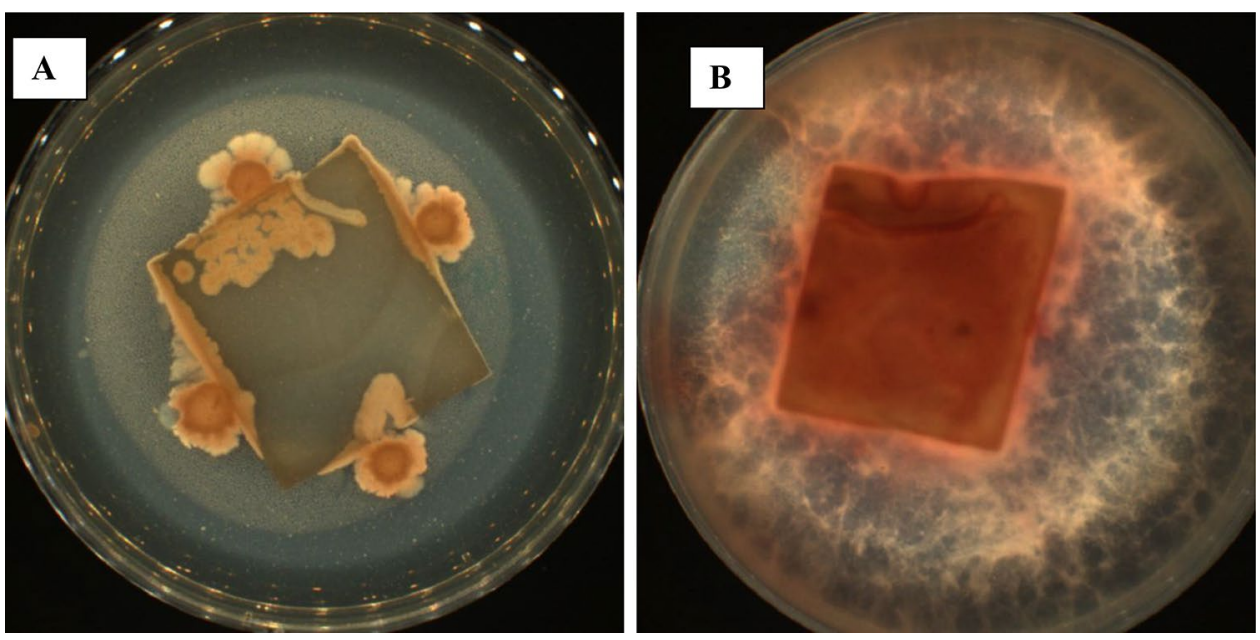

Fig. 11 SCA 50 inoculated with Bacillus sp. (a) and Fusarium culmorum (b) (a minimal medium amount for bacteria growing, b minimal medium amount for mushroom growing) after 2 weeks of incubation
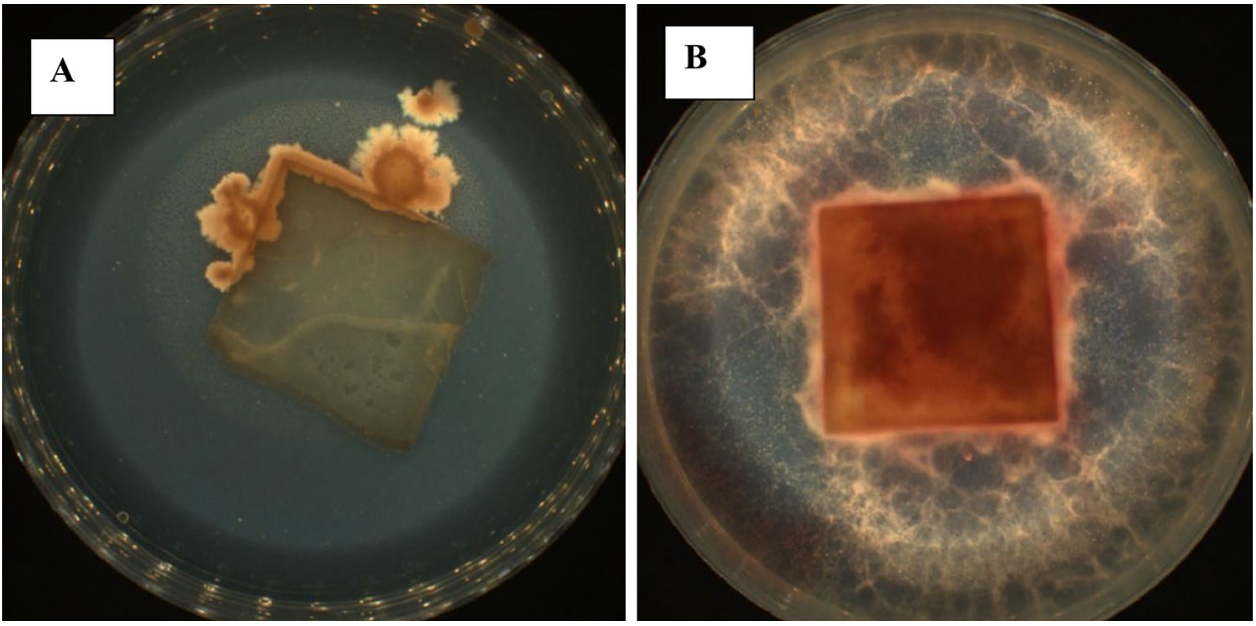
Fig. 12 SCA 10 residue after 2 weeks of Bacillus sp. (a) and F. culmorum (b) incubation and purification
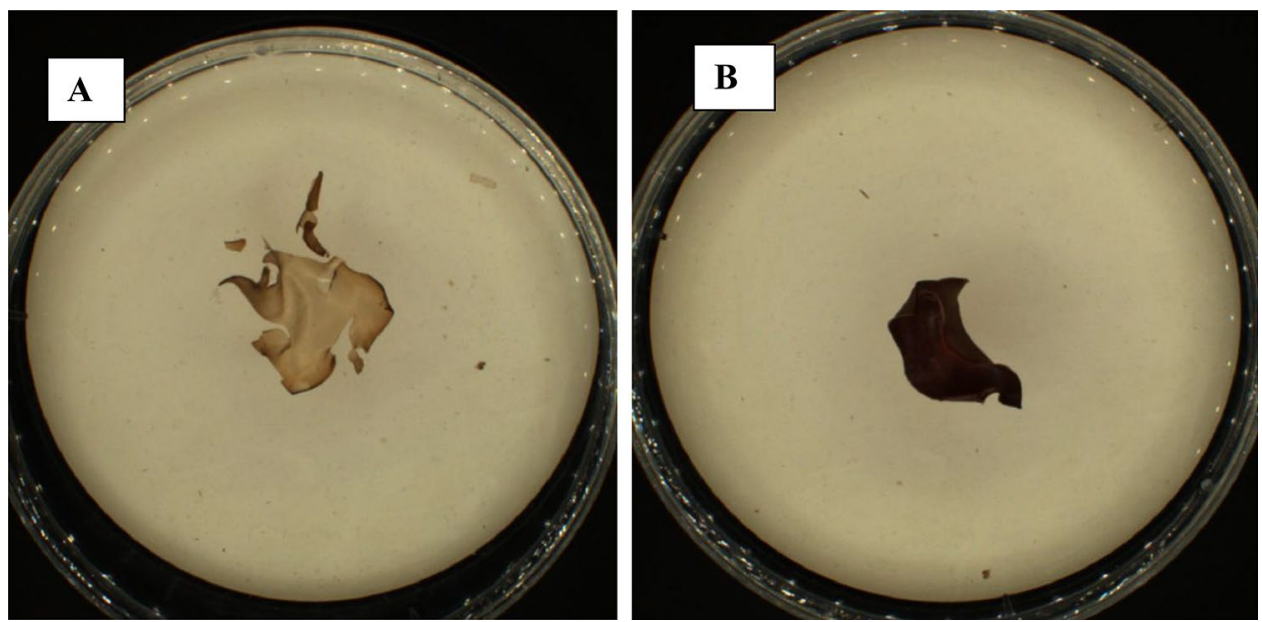

Fig. 13 SCA 50 residue after 2 weeks of Bacillus sp. (a) and Fusarium culmorum (b) incubation and purification
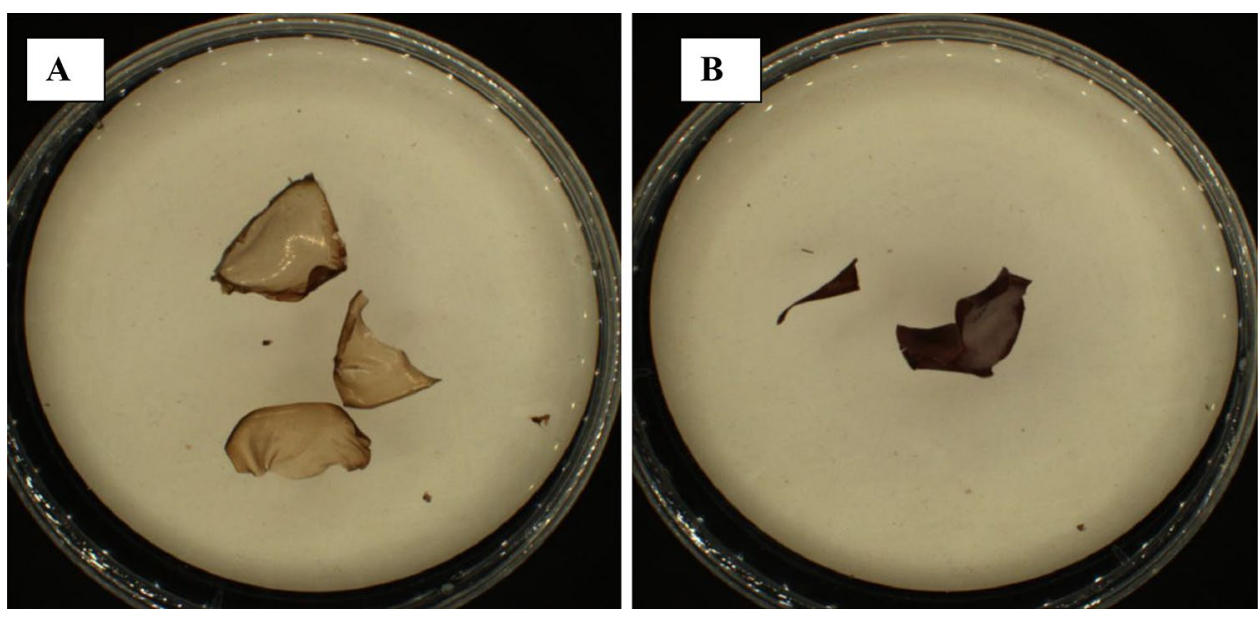

more than $50 \%$ of the examined area, while after two weeks, the SCA 10. samples were completely overgrown with mycelium, obtaining the highest 5 th grade according to the standard.

On the basis of the mass loss measurement, it was found that the samples were very strongly degraded, whereas in the presence of un-inoculated agar medium a weight loss of approx. $8 \%$ to $25 \%$ was observed after 2 weeks of incubation.

Mass loss values of bacteria-vaccinated (Bacillus sp.) films with $10 \%$ and $50 \%$ Aloe vera gel were $84.05 \%$ and $67.15 \%$, respectively, whereas, as a result of fungal activity (Fusarium culmorum), mass loss was lower ( $43.83 \%$ for SCA 10 , and $49.11 \%$ for SCA 50 ).

\section{Solubility in Water}

Water solubility is one of the most important aspects when commercial applicability of a material is expected [42, 43]. The incorporation of active antimicrobial agents into a starch matrix had no relevant effect on its water solubility. Different conclusions (decrease in WS with increasing
AV gel amount) have been drawn by Khoshgozaran-Abras S. at all [21]. Moreover, susceptibility to water is reduced when samples are subject to 24-h UV-irradiation, and these changes are most pronounced for the sample without Aloe vera as well as in film with its lowest concentration (10\% ww AV). When Aloe vera concentration in starch/chitosan blends reaches higher values (40-50\% ww.), the influence of radiation become less expressive (Table 6).

This behavior in hydrophilicity may be due to the fact that some new, cross-linked reaction between hydroxyl groups of starch, glycerol plasticizer, or/and amino groups in the protein present in the blend components occurred [42]. This crosslinking reaction affected by UV light may lead to tightening between all the matrix components, subsequently preventing water from penetration and limiting the blends solubility. Moreover, one can observe that the crosslinking rate caused by hydrogen bonding and the compactness of the network are related to Aloe vera concentration. A higher AV amount contributes to more intensive crosslinking formation after UV-irradiation and results in a decrease in a sample solubility. This conclusion remains in accordance with the 
Table 6 Water solubility (WS) determined as percentage loss of sample weight after its dissolution in water. All the samples were tested before and after 24-h UV-irradiation

\begin{tabular}{lll}
\hline Sample formulation & \multicolumn{2}{l}{$\begin{array}{l}\text { Loss of weight after dissolution } \\
\text { in water (\%) }\end{array}$} \\
\cline { 2 - 3 } & 0 h UV & 24 h UV \\
\hline SC & 90.91 & 84.20 \\
SCA 10 & 90.71 & 83.41 \\
SCA 20 & 84.38 & 84.99 \\
SCA 30 & 91.64 & 90.45 \\
SCA 40 & 90.41 & 88.66 \\
SCA 50 & 91.24 & 88.10 \\
\hline
\end{tabular}

results obtained with XRD spectroscopy and contact angle measurements. A similar effect as a result of hydrofobic dialdehyde starch incorporation into yam-starch biofilms was described by Oluwasina and co.[43].

\section{Conclusion}

Novel biodegradable composites based on starch modified with chitosan, Aloe vera gel and glycerol as a plasticizer with reproducible properties were obtained in an uncomplicated and economical process. The structure of the prepared films differing in the AV content and macromolecules arrangements have been studied by FTIR spectroscopy, microscopic techniques (SEM and AFM) and X-ray diffraction. It was found that intermolecular interactions which contribute to good transparency of the films occur.

The crystallinity degree of starch decreases in the presence of chitosan and AV up to $10 \mathrm{wt} \%$. However, higher concentrations of Aloe vera gel cause the opposite effect on crystallinity. Crystallinity degree determined by the XRD diffraction method was consistent with the results obtained by infrared FTIR spectroscopy (using crystallinity index i.e. $\mathrm{R}_{1}=1040 \mathrm{~cm}^{-1} / 1012 \mathrm{~cm}^{-1}$ absorbance ratio). The appropriate crystallinity degree of starch in the blend and the addition of the plasticizer ensures good flexibility of the films, which predisposes them to packaging applications.

Studies of the UV radiation influence and Thermogravimetric analysis have shown that the obtained composites are characterized by good thermal and photochemical stability. The higher the AV content in the samples, the better their resistance to UV. The main photo-processes (occurring with relatively low efficiency) are photo-oxidation and photo-destruction, as evidenced by the decreasing hydroxyl and increasing carbonyl indexes calculated form IR spectra.

The positive AV gel effect on the thermal stability of the composites determined on the basis of the shift temperature onset towards higher temperatures indicates structural reorganization or new bonds formation between components in the matrix (also thermally induced crosslinks). The good thermal resistance suggests the possibility of applying classical processing methods to form appropriate products.

AV also influences the surface properties of starch/chitosan blends, causing an increase in films polarity which, in turn, affects the samples solubility in water. In the case of UV-irradiated composites, AV leads to an increase in hydrophobicity, which can be caused by photo-crosslinking processes and closing molecular fragments with polar functional groups within cross-linked structures. It is confirmed by limited solubility of the samples in water.

A valuable information was provided by a microbiological test. The studied samples stimulated the growth of microorganisms, being a source of carbon for both, bacteria (Bacillus sp.) and fungi (Fusarium culmorum). All the samples underwent biodegradation processes, as was determined by measuring mass losses; however, this process was more intense for the starch/chitosan sample with the lowest Aloe vera gel amount.

Moreover, the tested samples turned out to be more susceptible to the bacterial (Bacillus sp.) rather than to fungal (F. culmorum) activity. This confirms that films with Aloe vera gel gain increased resistance to microbial activity, which is beneficial for packaging applications in food, cosmetics and pharmaceutical industries. Such materials will be able to provide a longer shelf life or usability of packaged products; and as they are made of completely biodegradable materials, they do not pose a threat to natural environment.

This research did not receive any specific grant from funding agencies in the public, commercial, or not-forprofit sectors.

Open Access This article is licensed under a Creative Commons Attribution 4.0 International License, which permits use, sharing, adaptation, distribution and reproduction in any medium or format, as long as you give appropriate credit to the original author(s) and the source, provide a link to the Creative Commons licence, and indicate if changes were made. The images or other third party material in this article are included in the article's Creative Commons licence, unless indicated otherwise in a credit line to the material. If material is not included in the article's Creative Commons licence and your intended use is not permitted by statutory regulation or exceeds the permitted use, you will need to obtain permission directly from the copyright holder. To view a copy of this licence, visit http://creativecommons.org/licenses/by/4.0/.

\section{References}

1. Perazzo KKNCL, de Vasconcelos ACC, dos Santos JCP, de Jesus AD, Souza CO, Druzian JI, (2014) Properties and antioxidant action of actives cassava starch films incorporated with green tea and palm oil extracts. PLoS ONE 9(9):105199. https ://doi.org/10.1371/journal.pone.0105199 
2. Hu X-P, Huang T-T, Mei J-Q, Jin Z-Y, Xu X-M, Chen H-Q, (2015) Effect of continuous and intermittent retrogradation treatments on in vitro digestibility and structural properties of waxy wheat starch. Food Chem 174:31-36

3. Nisara T, Wanga Z-C, Yanga X, Tiana Y, Iqbalb M, Guoa Y (2018) Characterization of citrus pectin films integrated with clove budessential oil: physical, thermal, barrier, antioxidant and antibacterial properties. Int J Biol Macromol 106:670-680

4. Zarski A, Bajer K, Zarska S, Kapusniak J (2019) From high oleic vegetable oils to hydrophobic starch derivatives: I development and structural studies. Carbohyd Polym 214:124-130

5. Menzela C, González-Martínez C, Chiralt A, Vilaplana F (2019) Antioxidant starch films containing sunflower hull extracts. Carbohyd Polym 214:142-151

6. Bajer D, Kaczmarek H, Bajer K (2013) The structure and properties of different types of starch exposed to UV radiation: a comparative study. Carbohyd Polym 98:477-482

7. Leceta L, Guerrero P, Ibarburu I, Dueñas MT, de la Caba K (2013) Characterization and antimicrobial analysis of chitosanbased films. J Food Eng 116:889-899

8. Mendes JF, Paschoalin RT, Carmona VB, Neto ARS, Marques ACP, Marconcini JM, Mattoso LHC, Medeiros ES, Oliveira JE (2016) Biodegradable polymer blends based on corn starch and thermoplastic chitosan proposed by extrusion. Carbohyd Polym $137: 452-458$

9. Lopez O, Garcia MA, Villar MA, Gentili A, Rodriguez MS, LAlbertengo L, (2014) Thermo-compression of biodegradable thermoplastic corn starch films containing chitin and chitosan. LWT- Food Sci Technol 57:106-115

10. Noorbakhsh-Soltani SM, Zerafat MM, Sabbaghi S (2018) A comparative study of gelatin and starch modified by nano-cellulose and chitosan for food packaging application. Carbohyd Polym 189:48-55

11. Liu XF, Huang YL, Yang DZ, Li Z, Yao KD (2001) Antibacterial action of chitosan and carboxymethylated chitosan. J Appl Polym Sci 79:1324-1335

12. Talon E, Trifkovic KT, Vargas M, Chiralt A, Gonzales-Martinez C (2017) Release of polyphenols from starch-chitosan based films containing thyme extract. Carbohyd Polym 175:122-130

13. Bonilla J, Talón E, Atarés L, Vargas M, Chiralt A (2013) Effect of the incorporation of antioxidants on physicochemical and antioxidant properties of wheat starch-chitosan films. J Food Eng 118:271-278

14. Leceta I, Guerrero P, de la Caba K (2013) Functional properties of chitosan-based films. Carbohyd Polym 93:339-346

15. Ray A, Dutta Gupta S, Ghosh S (2013) Evaluation of anti-oxidative activity and UV absorption potential of the extracts of Aloe vera $\mathrm{L}$ gel from different growth periods of plants. Ind Crop Prod 49:712-719

16. Minjares-Fuentes R, Femenia A, Comas-Serra F, RodríguezGonzález VM (2018) Compositional and structural features of the main bioactive polysaccharides present in the aloe vera plant. J AOAC Int 101(6):1711-1719

17. Medina-Jaramillo C, Ochoa-Yepes O, Bernal C, Fama L (2017) Active and smart biodegradable packaging based on starch and natural extracts. Carbohyd Polym 176:187-194

18. Mondal MIH, Saha J (2019) Antimicrobial, UV resistant and thermal comfort properties of chitosan- and Aloe vera-modified cotton woven fabric. J Polym Environ 27:405-420

19. Gutierrez TJ, Alvarez K (2016) Physico-chemical properties and in vitro digestibility of edible films made from plantian flour with added Aloe vera gel. J Funct Foods 26:750-762

20. Singh S, Anjum S, Joy J, Gupta B (2019) Polysaccharide-aloe vera bioactive hydrogels as wound care system in cellulosebased superabsorbent hydrogels, polymers and polymeric composites: a reference series, M. I. H. Mondal (ed) Springer Nature, Switzerland AG: 1473-1490

21. Khoshgozaran-Abras S, Azizi MH, Hamidy Z, BagheripoorFallah N (2012) Mechanical, physicochemical and color properties of chitosan based-films as a function of Aloe vera gel incorporation. Carbohyd Polym 87:2058-2062

22. Silva SS, Popa EG, Gomes ME, Cerqueira M, Marques AP, Caridade SG, Teixeira P, Sousaa C, Mano JF, Reis RL (2013) An investigation of the potential application of chitosan/aloebased membranes for regenerative medicine. Acta Biomater 9:6790-6797

23. Kowalonek J, Surface and thermal behavior of chitosan/ poly(ethylene oxide) blends (2016) Mol Cryst Liq Cryst 640 (1): 78-89

24. Owens DK, Wendt RC (1969) Estimation of the surface free energy of polymers. J Appl Polym Sci 13:1741-1747

25. Romero-Bastida CA, Bello-Perez LA, Garcia MA, Martino MN, Solorza-Feria J, Zarintzky NE (2005) Physicochemical and microstructural characterization of films prepared cellulosic by thermal and cold gelatinization form non-conventional sources of starches. Carbohyd Polym 60(2):235-244

26. Torres-Giner S, Wilkanowicz S, Melendez-Rodriguez B, Lagaron JM (2017) Nanoencapsulation of Aloe vera in Synthetic and naturally occurring polymers by Electrohydrodynamic processing of interest in food technology and bioactive packaging. $\mathrm{J}$ Agr Food Chem 65:4439-4448

27. Guoa J, Liua L, Lianb X, Lic L, Wu H (2014) The properties of different cultivars of Jinhai sweet potato starches in China. Int J Biol Macromol 67:1-6

28. van Soest JJG, Tournois H, de Wit D, Vliegenthart JFG (1995) Short-range structure in (partially) crystalline potato starch determined with attenuated total reflectance Fourier-transform IR spectroscopy. Carbohyd Res 279:201-214

29. Kaczmarska K, Grabowska B, Spychaj T, Zdanowicz M, Sitarz M, Bobrowski A, Cukrowicz S (2018) Effect of microwave treatment on structure of binders based on sodium carboxymethyl starch: FT-IR. FT-Raman and XRD investigation, Spectrochim Acta A Mol Biomol Spectrosc 199:387-393

30. Sevenou O, Hill SE, Farhat IA, Mitchell JR (2002) Organization of the external region of the starch granule as determined by infrared spectroscopy. Int J Biol Macromol 31:79-85

31. Warren FJ, Gidley MJ, Flanagan BM (2016) Infrared spectroscopy as a tool to characterize starch ordered structure-a joint FTIR-ATR, NMR, XRD and DSC study. Carbohyd Polym 139:35-42

32. Branca C, Angelo G, Crupi C, Khouzami K, Rifici S, Ruello G, Wanderlingh U (2016) Role of the $\mathrm{OH}$ and $\mathrm{NH}$ vibrational groups in polysaccharide-nanocomposite interactions: A FTIR-ATR study on chitosan and chitosan/clay films. Polymer 99:614-622

33. Brown CD, Kreilgaard L, Nakakura M, Caram-Lelham N, Pettitb DK, Gombotzb WR (2001) Release of PEGylated granulocyte-macrophage colony stimulating factor from chitosan/glycerol films. J Control Release 72:35-46

34. Lavorgna M, Piscitelli F, Mangiacapra P, Buonocore GG (2010) Study of combined effect of both clay and glycerol plasticizer on the properties of chitosan films. Carbohyd Polym 82:291-298

35. Brugnerotto J, Lizardi J, Goycoolea FM, Argüelles-Monal W, Desbrières J, Rinaudo M (2001) An infrared investigation in relation with chitin and chitosan characterization. Polymer 42(8):3569-3580

36. Aldao DC, Sarka E, Ulbrich P, Mensikova E (2018) Starch nanoparticles - two ways of their preparation. Czech J Food Sci Food Technol Econ Eng Phys Prop 36 (2): 133-138 
37. Liu H, Chaudhary D, Yusa S, Tade MO (2011) Glycerol/starch/ Na+-montmorillonite nanocomposites: a XRD, FTIR, DSC and ${ }^{1}$ H NMR study. Carbohyd Polym 83:1591-1597

38. Marimuthu M, Sundaram U, Gurumoorthi P (2013) X-ray diffraction and starch analysis of nano sized seed powder of velvet bean (Mucuna pruriens). Indo Am J Pharm Res 3(6):4319-4329

39. Popescu MC, Dogaru BI, Goanta M, Timpu D (2018) Structural and morphological evaluation of CNC reinforced PVA/starch biodegradable films. Int J Biol Macromol 116:385-439

40. Cucinelli Neto RP, da Rocha REJ, Bruno Tavares MJ (2018) Proton NMR relaxometry as probe of gelatinization, plastification and montmorillonite-loading effects on starch-based materials. Carbohyd Polym 182:123-131

41. Kowalonek J (2017) Surface and thermal properties of UV-irradiated chitosan/poly(ethylene oxide) blends. J Photochem Photobiol A Chem 348(1):209-218
42. Gutierrez JT, Tapia MS, Perez E, Fama L (2015) Edible films based on native and phosphated 80:20 waxy: normal corn starch. Starch/Starke 67:90-97

43. Oluwasina OO, Falola T, Wahab OJ (2018) Enhancement of physical and mechanical properties of Diosecorea Dumetorum starch films with dialdehyde starch solution. Starch/Starke 70:1-7

Publisher's Note Springer Nature remains neutral with regard to jurisdictional claims in published maps and institutional affiliations. 